University of Louisville

ThinkIR: The University of Louisville's Institutional Repository

Electronic Theses and Dissertations

$12-2019$

\title{
Involuntary memories after stressor exposure: contribution of hormonal status and rumination in women.
}

\author{
Samantha C. Patton \\ University of Louisville
}

Follow this and additional works at: https://ir.library.louisville.edu/etd

Part of the Clinical Psychology Commons

\section{Recommended Citation}

Patton, Samantha C., "Involuntary memories after stressor exposure: contribution of hormonal status and rumination in women." (2019). Electronic Theses and Dissertations. Paper 3346.

https://doi.org/10.18297/etd/3346

This Doctoral Dissertation is brought to you for free and open access by ThinkIR: The University of Louisville's Institutional Repository. It has been accepted for inclusion in Electronic Theses and Dissertations by an authorized administrator of ThinkIR: The University of Louisville's Institutional Repository. This title appears here courtesy of the author, who has retained all other copyrights. For more information, please contact thinkir@louisville.edu. 
INVOLUNTARY MEMORIES AFTER STRESSOR EXPOSURE: CONTRIBUTION

\title{
OF HORMONAL STATUS AND RUMINATION IN WOMEN
}

\author{
By \\ Samantha C. Patton \\ B.A., University of Memphis, 2010 \\ M.S., University of Louisville, 2016

\begin{abstract}
A Dissertation
Submitted to the Faculty of the

College of Arts and Sciences of the University of Louisville in Partial Fulfillment of the Requirements

for the Degree of
\end{abstract}

Doctor of Philosophy

in Clinical Psychology

Department of Psychological and Brain Sciences

University of Louisville

Louisville, Kentucky

December 2019 

INVOLUNTARY MEMORIES AFTER STRESSOR EXPOSURE: CONTRIBUTION OF HORMONAL STATUS AND RUMINATION IN WOMEN

By

\author{
Samantha C. Patton \\ B.A., University of Memphis, 2010 \\ M.S., University of Louisville, 2016
}

A Dissertation Approved on

August 21, 2019

by the following Dissertation Committee:

Tamara L. Newton, Ph.D.

Brendan E. Depue, Ph.D.

Keith B. Lyle, Ph.D.

Stephen S. O'Connor, Ph.D.

Sandra Sephton, Ph.D. 


\title{
ABSTRACT \\ INVOLUNTARY MEMORIES AFTER STRESSOR EXPOSURE: CONTRIBUTION OF HORMONAL STATUS AND RUMINATION IN WOMEN
}

\author{
Samantha C. Patton
}

August 21, 2019

Women experience fewer traumatic stressors over their lifespan than men, but demonstrate a higher prevalence of major depression and stressor-related disorders as a result of trauma exposure (Breslau \& Anthony, 2007; Kessler et al., 2005). Differences in prevalence of stressor-related disorders may partially be due to sex-linked vulnerabilities related to emotional memory. Emotion assists in modulation of memory through neurological processes. This modulation enhances memory for emotional stimuli and can lead to a greater frequency of involuntary recall after stressor exposure. This involuntary memory is also a hallmark symptom of Posttraumatic Stress Disorder (PTSD). Sex-linked vulnerabilities, specifically hormonal status and frequency of brooding rumination may contribute to a higher prevalence of PTSD in women following stress exposure through their influence on emotional memory processes. The current study further examined these potential sex-linked vulnerabilities in 77 (43 hormonal contraceptive users and 34 naturally cycling) women. Participants were asked to report on their experience of involuntary memories each evening for seven days following exposure to a trauma analogue film. Contrary to hypotheses, neither hormonal contraceptive status nor 
brooding rumination were statistically significant predictors of involuntary memory frequency, related distress, or related activity interference during the seven day followup. Severity of depressive symptoms was the only statistically significant predictor in all tested models. Findings further highlight current depressive symptoms, as a robust vulnerability factor for developing intrusive memories following stressor exposure. 


\section{TABLE OF CONTENTS}

PAGE

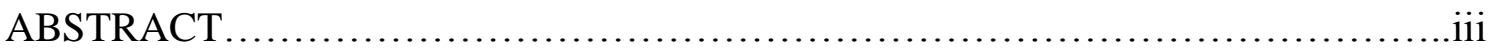

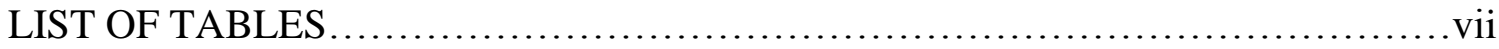

LIST OF FIGURES ..........................................................

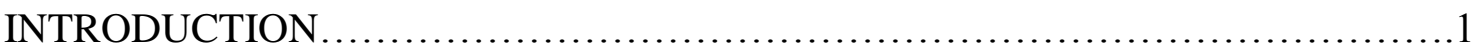

Memory and the Mnemonic Model.....................................2

Hormonal Status and Emotional Memory..................................4

Rumination........................................................ 11

Aims of the Current Study.......................................... 14

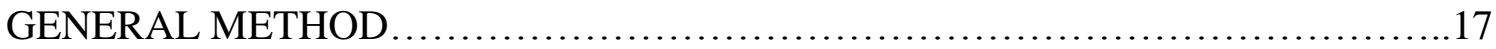

Study Design...................................................17

Participant Recruitment and Compensation...............................18

Eligibility....................................................... 18

Procedure.......................................................... 19

Materials and Measures................................................20

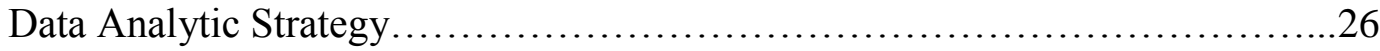

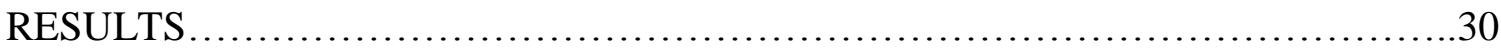

Sample.......................................................... 30

Psychopathology, Rumination, and Worry.............................. 31

Responses to the Film............................................ 32

Involuntary Memories: Frequency, Distress, and Interference with Activity as a

Product of the Trauma Analogue Film...................................33

Hormonal Status, Trait Brooding rumination, and Involuntary Memory..........33 
Ancillary Analyses.................................................. 34

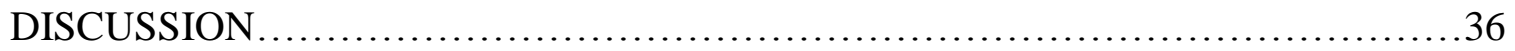

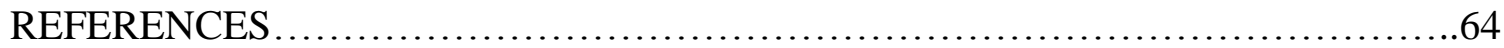

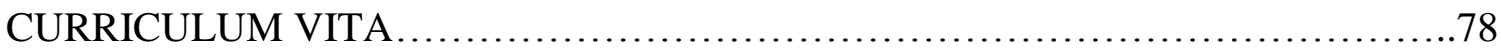




\section{LIST OF TABLES}

TABLES

PAGE

1. Zero-Order spearman correlations for self-report variables used in hierarchical

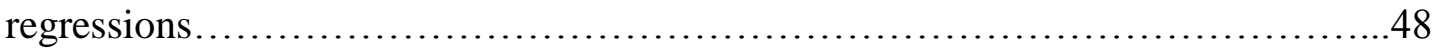

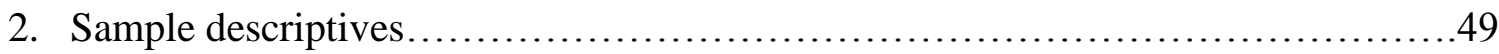

3. Sample psychopathology, rumination, and worry .............................50

4. Attention, state affect, and cardiovascular variables.............................51

5. Predicting involuntary memory frequency in $\mathrm{HC}$ users and $\mathrm{NC}$ women.............52

6. Predicting involuntary memory related distress in $\mathrm{HC}$ users and $\mathrm{NC}$ women........53

7. Predicting involuntary memory related interference in $\mathrm{HC}$ users and $\mathrm{NC}$ women....54

8. Predicting combined total frequency and intensity of involuntary memories in $\mathrm{HC}$

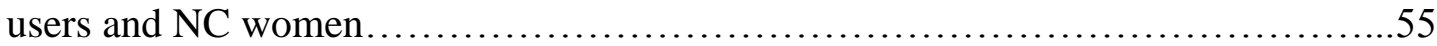

9. Predicting involuntary memory frequency in $\mathrm{HC}$ users, LF women, and FF women.56

10. Predicting involuntary memory related distress in HC users, LF women, and FF

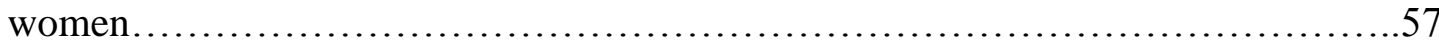

11. Predicting involuntary memory related interference in HC users, LF women, and FF

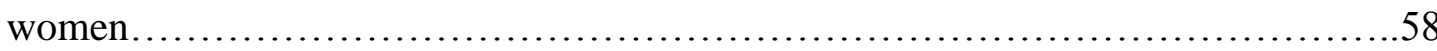

12. Predicting combined total frequency and intensity of involuntary memories in HC

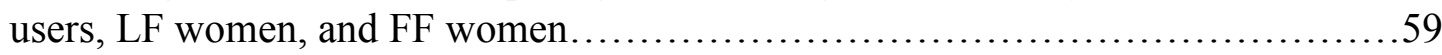




\section{LIST OF FIGURES}

FIGURE

PAGE

1. Comparison of hormone levels in naturally cycling women compared to those taking

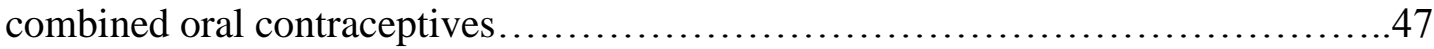

2. Involuntary memory frequency over one week follow-up $\ldots \ldots \ldots \ldots \ldots \ldots \ldots \ldots \ldots \ldots$

3. Intensity of distress experienced as a result of involuntary memories over one week follow-up...........................................................61

4. Intensity of interference caused by involuntary memories over one week follow-up.62

5. Combined total frequency and intensity of involuntary memories over one week

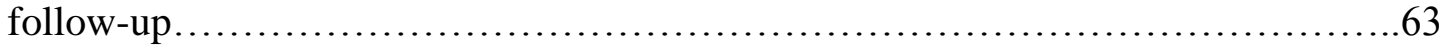




\section{INTRODUCTION}

Stress and trauma are relatively common experiences. A recent epidemiological study showed that $89.7 \%$ of those sampled experienced at least one traumatic event as defined by the Diagnostic and Statistical Manual of Mental Disorders, Fifth Edition (American Psychiatric Association, 2013) and most experienced more than one event (Kilpatrick et al., 2013). However, exposure to a traumatic event does not mean that an individual will develop psychopathology. For example, women are reported to have lower rates of trauma exposure than their male counterparts, yet have higher rates of major depression and stressor-related disorders (Breslau \& Anthony, 2007; Kessler et al., 2005). When experiencing the same type of stressor as men, women have twice the likelihood of developing posttraumatic stress disorder (PTSD) (Stein, Walker, \& Forde, 2000; Tolin \& Foa, 2006) and are more likely to experience comorbid depression or anxiety (Orsillo, Raja, \& Hammond, 2002). Specific symptoms also differ by sex, with some re-experiencing symptoms (e.g., distress from reminders of the event and physical reactivity to memories of the event) reported to be more common in women (Carmassi et al., 2014; Fullerton et al., 2001; Hourani, Williams, Bray, \& Kandel, 2015).

One reason for this overall gap between men and women in affective and stressorrelated disorder prevalence may be interactions between sex-linked vulnerabilities influencing emotion and memory. The focus of the present study was on hormonal status 
and trait rumination as sex-linked variables of interest. Main effects of hormonal status and trait rumination as well as the interaction between these variables were examined in their association with involuntary memory following exposure to an analogue trauma. Frequency of involuntary memories, distress associated with involuntary memories, and interference with current activities caused by involuntary memories were examined. Better understanding these vulnerabilities and the association they share with emotion and memory will lead to better prevention efforts for trauma-related disorders in women.

\section{Memory and the Mnemonic Model of PTSD}

The traditional approach to PTSD involves investigating how a traumatic event interacts with predisposing factors to produce symptoms. Using this approach, a substantial amount of weight is given to the specifics of the event and less importance is

placed on the individual (Rubin, Bernsten, Bohni, 2008). In contrast, the mnemonic model of PTSD asserts that the etiology and maintenance of PTSD symptoms are a function of the current memory of an event rather than the event itself. This model draws upon memory research and basic science to examine how memory is created and maintained in extreme situations rather than making claims that traumatic memory is unique. The latter is often suggested within the traumatic stress literature, but this claim lacks a secure foundation in basic science.

Recurrent, distressing, involuntary memories of the trauma are a hallmark symptom of PTSD. In general, memories are either recalled, or "brought to mind", intentionally or unintentionally. Voluntary recall of a memory is an intentional, effortful process, whereas involuntary recall is unintentional, effortless and unpredictable. In part 
due to the unpredictable nature of these memories, involuntary memories cause greater distress than memories recalled intentionally (Rubin, Boals, \& Berntsen, 2008).

The availability of these involuntary memories can be increased through modulatory processes occurring at encoding. Important to the mnemonic model is the modulatory relationship that amygdala function has with enhanced memory for emotional stimuli. Degree of amygdala activation during encoding is positively associated with long-term memory in fMRI (Murty, Ritchey, Adcock, \& LaBar, 2010) and positron emission tomography studies (Cahill et al., 1996). Research done in both humans and animals with lesions of the amygdala also suggests a modulatory influence of amygdala activation on long-term memory, with amygdala involvement resulting in enhanced memory (McGaugh, Cahill, \& Roozendaal, 1996). This modulation at encoding, in turn, allows for greater availability and accessibility of the memory. This increased accessibility contributes to a greater number of involuntary and voluntary memories of the event (Rubin et al. 2008). Therefore, factors that alter degree of amygdala activity in response to emotional stimuli, such as hormonal status and differences in affective regulatory strategy, likely alter memory availability and increase the frequency of involuntary recall.

Critically, differences are frequently seen between men and women in autobiographical emotional memory, with women at increased risk for more frequent voluntary and involuntary memories of a stressful event (Rubin et al., 2008). This difference makes sex an important factor within the mnemonic model. Generally, women report greater arousal in response to, as well as enhanced memory for, emotional stimuli than men (Bradley, Codispoti, Sabatinelli, \& Lang, 2001; Canli, Desmond, Zhao, \& 
Gabrieli, 2002). However, this is not always demonstrated (Rubin, Schulkind, \& Rahhal, 1999). One reason for this discrepancy among studies may be unaccounted for differences in hormonal status in female participants as well as differences in affective regulatory strategy, both of which relate to amygdala functioning.

\section{Hormonal Status and Emotional Memory}

Throughout their reproductive lives, women experience circulating levels of estrogen and progesterone that fluctuate throughout a typical month. However, some women utilize hormonal contraceptives, altering this cyclical pattern. In either case, these circulating gonadal hormones have the potential to impact emotion and memory through interactions with neurotransmitter systems (Barth, Villringer, \& Sacher, 2015), altering of brain structure and connectivity (Hagemann et al., 2011; Pletzer et al., 2010;

Protopopescu et al., 2005; Protopopescu et al., 2008), as well as through more direct routes. Specifically, the amygdala and hippocampus express large quantities of estrogen and progesterone receptors (Brinton, et al., 2008; Gillies \& McArthur, 2010). Thus, gonadal hormones may influence brain functioning and ultimately behavior through direct and indirect effects on these areas of the brain.

The menstrual cycle and endogenous hormones. The average menstrual cycle length is between 23 and 32 days in the human woman (Cole, Ladner, \& Byrn, 2009). As shown in Figure 1, this cycle is divided into the follicular and luteal phases. The follicular phase contains menses as well as the proliferative portion of the menstrual cycle, while the luteal phase is also known as the secretory phase. Ovulation separates these two phases, and fourteen days later menstruation marks the beginning of a new cycle. 
Estrogen and progesterone levels are at their lowest in the early follicular phase, during menses. Estrogen then begins to climb after the cessation of menses and peaks before ovulation. After ovulation, estrogen dips and then rises with progesterone during the luteal phase, but not to the level achieved before ovulation. Progesterone remains low and stable through the follicular phase and begins to rise after ovulation. Progesterone peaks during the luteal phase while estrogen is also elevated. In the final week of the luteal phase, progesterone and estrogen both decline, triggering menstruation.

The menstrual cycle and emotional memory. Naturally cycling (NC) women, particularly those in the luteal phase at the time of encoding, experience a greater frequency of involuntary memories after experiencing a stressful event when compared to men and to women in the follicular phase. This luteal phase vulnerability has been shown in experimental studies where the number of involuntary memories experienced was retrospectively reported 48 hours (Ferree \& Cahill, 2009; Ferree, Kamat, \& Cahill, 2011) or 72 hours (Soni, Curran, \& Kamboj, 2013) after stressor exposure. More frequent involuntary memories in the form of flashbacks have also been shown in an observational study in which women admitted to the hospital for traumatic injury were given the Clinician Administered PTSD scale approximately a week after their injury (Bryant et al., 2011). This greater frequency of involuntary memories is thought to be due in part to increased progesterone levels that characterize much of the luteal phase. In support of this, progesterone levels at encoding have also been associated with enhanced memory for emotional stimuli in laboratory studies (Ertman, Andreano, \& Cahill, 2011).

Additional studies have been conducted using estrogen levels to predict involuntary recall after stress exposure. Women with lower estrogen levels in either 
phase experienced a greater frequency of involuntary memories when compared to women with high levels of estrogen in either phase, while progesterone levels were not found to be predictive (Cheung, Chervonsky, Felmingham, \& Bryant, 2013; Wegerer, Kerschbaum, Blechert, \& Wilhelm, 2014). However, these results do not indicate a simple relationship. Estrogen and progesterone may antagonize each other's effect, and so absolute levels of either hormone may not be a good predictor of involuntary memory frequency (Bäckström et al., 2011).

To resolve conflicting findings related to the predictive power of estrogen or progesterone alone, Soni and colleagues (2013) utilized the ratio of estrogen to progesterone to predict frequency of involuntary memories of a trauma analogue film as well as different characteristics of the recalled memory. Using procedures common to studies of the relationship between the menstrual cycle and post-stressor involuntary memories, researchers exposed participants to an analogue trauma film at either the midfollicular, the early luteal, or the late luteal points of the menstrual cycle. The film used as an analogue trauma depicted five real-life scenes of death, mutilation, and severe injury. Unlike the Bryant or Cahill group studies, women completed an online diary where they recorded involuntary memories experienced each day. Three days after exposure, women exposed to the film in the early luteal phase reported more frequent involuntary memories of the film when compared to those in the late luteal and midfollicular phases at the time of encoding. There was no statistically significant difference in involuntary memory frequency when women in the late luteal and mid-follicular phases were compared. Further, the frequency of involuntary memories of the film was negatively correlated with the estrogen to progesterone ratio present in saliva. 
Progesterone is at higher levels than estrogen throughout the majority of the luteal phase. Thus, these findings provide additional support for the theory that higher levels of progesterone influence long-term memory for emotional stimuli.

Also reported by Soni et al. (2013), distress associated with involuntary memories, vividness of the memories, and feeling as though participants were reexperiencing the film were increased when women were exposed to the film during the early luteal phase compared to women in the late luteal and mid-follicular phases. However, these findings did not reach statistical significance. This may have been due to low power given the small sample size used in this study $(n=40)$. Effect sizes (cohen's d) comparing the mid-follicular and early luteal phases in distress, vividness, and feelings of re-experiencing were $0.55,0.52$, and 0.44 respectively.

In sum, in NC women, stress exposure during the luteal phase is consistently linked to greater frequency of involuntary memories of the stressor up to a week after exposure. This vulnerability is most apparent in the early luteal phase, when progesterone levels surpass estrogen levels. However, not all women are NC. Altering this monthly cycle may also have implications for emotional memory.

Hormonal contraceptives. Between 2006 and 2010, 88\% of sexually active women of reproductive age were reported to be using a hormonal method of contraception (Daniels \& Mosher, 2013). In addition to using exogenous hormones to prevent pregnancy, some women use these hormones to suppress menstruation. While a clearly important aspect of women's health, the psychological influence these formulations have on their users is not well known (Montoya \& Bos, 2017; Pletzer \& Kerschbaum, 2014). 
Hormonal contraceptive use lowers levels of circulating endogenous estrogen and progesterone (D'Arpe et al., 2016). The exact levels of circulating gonadal hormone differ by contraceptive formulation, but progesterone levels throughout the month are often comparable to women in the early follicular phase (Elliott-Sale et al., 2012; Marečková et al., 2014; Petersen, Kilpatrick, Goharzad, \& Cahill, 2014) (see Figure 1).

Hormonal contraceptives are either progestin only or combined (containing estradiol and progestin) in formulation. Researchers examining the impact of hormonal contraceptive use typically examine hormonal contraceptive users without regard to formulation, or limit their sample to only women using a combined formulation. Combined oral contraceptive users are the easiest to recruit, with $82 \%$ of contraceptive using women reporting using this method between 2006 and 2010 (Daniels \& Mosher, 2013). The use of this hormonal status group allows for better specificity than recruiting women using any type of hormonal contraceptive. Unfortunately as a side effect, little is known about the impact of progestin only formulations or of hormonal contraception that is not taken in pill form. Nevertheless, this research helps us to begin to understand how hormonal contraceptives may influence psychological processes.

Hormonal contraceptives and emotional memory. Because hormonal contraceptive use lowers circulating estrogen and progesterone levels, it would be predicted that contraceptive users show encoding of emotional stimuli more similar to that demonstrated by women in the follicular phase than those in the early luteal phase. Research to date does indicate differences in emotional memory between those using hormonal contraceptives and NC women, particularly in the luteal phase (Ferree, 
Wheeler, \& Cahill, 2012; Nielsen, Ertman, Lakhani, \& Cahill, 2011; Nielsen, Segal, Worden, Yim, \& Cahill, 2013). However, much remains unexamined.

Laboratory studies have examined differences between hormonal contraceptive users and $\mathrm{NC}$ women in some aspects of emotional memory, but not involuntary recall. Women taking hormonal contraceptives differ from $\mathrm{NC}$ women in any phase in their memory for emotional stories. Specifically, a week after exposure to emotional stories, $\mathrm{NC}$ women recalled more details and combined hormonal contraceptive users recalled more central information or "gist" (Nielsen et al., 2011). In these studies a main effect of hormonal status on voluntary recall was not seen. However, it should be noted that NC women in the luteal phase were taken from any point within this phase.

In a particularly relevant observational study, women taking any hormonal contraceptives or those electing to take an emergency contraceptive in the acute aftermath of a sexual assault reported significantly fewer involuntary memories in the form of PTSD intrusion symptoms related to the trauma six months post-assault when compared to NC women in any phase (Ferree et al., 2012). These results were interpreted to mean that hormonal contraceptive use in the acute aftermath of a traumatic event reduces posttraumatic stress symptoms, particularly intrusion symptoms, following sexual assault via the influence of gonadal hormones. This study did rule-out the possibility that these results were due to features of the assault likely to contribute to PTSD, such as the number of perpetrators involved, whether the perpetrator was known to the victim, whether alcohol was involved, whether consciousness was lost, whether a weapon was used, and whether physical violence or threats were used. However, this study did not address another important alternative interpretation. Specifically, researchers did not 
examine whether fear of pregnancy differed between women who refused emergency contraceptives and were not taking a hormonal contraceptive versus those using hormonal contraceptives or emergency contraception following assault. This fear could contribute to involuntary memory via increased arousal and negative affect during and after the assault. This fear could also be related to greater levels of anxiety and a greater frequency of worry about becoming pregnant. To my knowledge, this is the only study to examine involuntary memories, although in the form of intrusion symptoms, in women taking hormonal contraceptives following stress exposure.

Hormones and the amygdala. Hormonal status influences behavior through hormonal impact on degree of amygdala activation. The luteal phase, compared to the early follicular phase, is associated with greater activation of the amygdala and hippocampus in imaging studies using emotional tasks (Andreano \& Cahill, 2010; Bayer, Schultz, Gamer, \& Sommer, 2014; Goldstein et al., 2005). Higher progesterone levels at encoding have specifically been associated with greater amygdala activation in response to emotional stimuli (Andreano \& Cahill, 2010).

Limited research demonstrates that the suppression of circulating endogenous estrogen and progesterone through the use of hormonal contraceptives also has implications for amygdala functioning. Women using hormonal contraceptives showed decreased amygdala reactivity to negatively valenced stimuli when compared to NC women in the follicular and luteal phases (Petersen \& Cahill, 2014).

Given the available information, hormonal status may indeed be one factor that helps to explain sex differences, or lack thereof, in emotional memory across studies. Conceivably, it may also contribute to sex differences in prevalence rates of disorders 
involving emotional memory. However, additional factors likely contribute to these relationships and also require further consideration. Affective regulatory style, rumination in particular, is one additional factor that may be of significance in women.

\section{Rumination}

Rumination is often cited as a maladaptive, affective regulatory style characterized by perseverating on distress, causes of distress, or consequence of distress. This passive, abstract affective regulatory style has been specifically labeled brooding rumination, while reflection or pondering (intellectual rumination) is another measured aspect of rumination not positively linked to psychopathology outcomes and more closely linked to problem solving (Treynor, Gonzalez, \& Nolen-Hoeksema, 2003). Brooding rumination is a trait-like regulatory style that is stable in those who report more habitual use, even if symptoms of psychopathology are seen to change (Kuehner \& Weber, 1999; Nolen-Hoeksema, Morrow, \& Fredrickson, 1993).

Women report ruminating at a greater frequency when compared to men (NolenHoeksema, 2012; Rood, Roelofs, Bögels, Nolen-Hoeksema, \& Schouten, 2009). Women endorse both a greater frequency of brooding and reflection when compared to male counterparts (Johnson \& Whisman, 2013). Alone, this established difference suggests that rumination is an important sex-linked affective variable worthy of further study. In addition to higher frequencies of reported rumination in women, rumination mediates depression and anxiety symptoms in women and brooding rumination specifically mediates depression symptoms in women (Treynor et al., 2003). Being a woman is related to greater depression and anxiety symptoms, and this relationship between sex and symptoms is weakened once rumination is accounted for (Johnson \& Whisman, 
2013; Nolen-Hoeksema, 2012; Rood et al., 2009; Tamres, Janicki, \& Helgeson, 2002). Though sex did not account for variability in effects reported by studies examining rumination and PTSD symptoms within a recent meta-analysis (Szabo, Warnecke, Newton, \& Valentine, 2017), rumination, particularly brooding rumination, may play an important role in observed sex differences after the experience of a trauma.

In trauma literature, rumination is measured as either state, trauma-focused or trait, not necessarily trauma-focused. However, how important this distinction is remains to be seen. An analysis examining consistency across multiple potential measures of rumination found high consistency across all included measures $(\alpha=0.90)$ suggesting these measures of different aspects of rumination converge on a similar factor (Siegle, Moore, \& Thase, 2004). However, this same study found weak $(r=0.31-0.35)$ correlations between trait brooding and event-focused or state measures of rumination (Siegle et al., 2004).

Rumination has been shown to predict PTSD symptoms, with trait rumination demonstrating larger effects than trauma-focused rumination (Szabo et al., 2017). Of particular relevance to this proposal, rumination shares a strong relationship with intrusion symptoms, stronger than relationships shared with avoidance or hyperarousal symptoms (Szabo et al., 2017). Brooding rumination specifically is not often the focus in this literature.

Rumination and emotional memory. Rumination has the potential to influence involuntary memory through two routes; as a pre-stressor vulnerability factor involving trait levels of rumination and as a post-stressor maintenance factor involving rumination in response to involuntary memory. Regarding the first route, trait rumination is 
associated with increased frequency of involuntary stressor-related memories after stress exposure in observational (Smets, Luyckx, Wessel, \& Raes, 2012) and experimental (Kubota, Nixon, \& Chen, 2014; Watkins, 2004) studies. However, trait rumination is not often examined as a primary predictor of involuntary recall in experimental studies, and similarly brooding rumination is typically not parsed out. More frequently, stimulifocused rumination is manipulated within the lab or rumination in response to involuntary memories is measured. Rumination as a response to involuntary recall (Laposa \& Rector, 2012; Smets et al., 2012) or to stressor exposure (Kubota et al., 2014; Watkins, 2004) also predicts increased frequency of involuntary memories. Thus, this body of research indicates that rumination can be viewed as a pre-trauma vulnerability factor via measures of trait rumination, as well as a maintenance factor that sustains pathological memory via rumination in response to involuntary recall or stressor exposure. Because the present proposal concerns sex-linked vulnerability factors, the role of trait rumination as a prestressor vulnerability factor will be examined.

Potential mechanisms. Rumination is associated with longer periods of more intense distress (Blagden \& Craske, 1996; McLaughlin, Borkovec, \& Sibrava, 2007; Nolen-Hoeksema et al., 1993). Being associated with prolonged and more intense negative affect, it is unsurprising that this affective regulatory style is also positively correlated with amygdala activity during exposure to negatively valenced stimuli in healthy (Ray et al., 2005) and depressed individuals (Mandell, Siegle, Shutt, Feldmiller, \& Thase, 2014).

In addition, brooding and reflective rumination are associated with different functional connectivity patterns in healthy and depressed women at rest (Satyshur, 
Layden, Gowins, Buchanan, \& Gollan, 2018). Brooding rumination has been associated with increased connectivity between the posterior and subgenual cingulate cortex at rest, before and after controlling for depressive symptoms (Berman et al., 2011) as well as decreased functional connectivity between the left amygdala and right temporal pole (Satyshur et al., 2018). This pattern of connectivity further illustrates the role brooding rumination may play in enhanced amygdala activation leading to enhanced memory modulation following stressor exposure.

In sum, rumination is an affective regulatory style that is stable and more prevalent in women. Due to the relationship trait rumination shares with intrusive reexperiencing symptoms as well as overall PTSD symptoms, rumination is likely one factor that may help explain why women have higher rates of PTSD than men after stressor exposure. Examining rumination, particularly brooding rumination, along with hormonal status may be especially illuminating when measuring involuntary recall and resulting distress in women exposed to a stressor.

\section{Aims of the Current Study}

The first aim of this study was to examine the main effects of hormonal status (contraceptive use) on frequency of involuntary memories of a trauma analogue film, adding to the growing knowledge about hormonal contraceptive use and how this use may increase or lower vulnerabilities shown to be present in women of childbearing age. The association between hormonal contraceptive use status and involuntary memory recall following stressor exposure has not been examined in a laboratory environment. It was hypothesized that hormonal contraceptive users would demonstrate a lower mean 
frequency of involuntary memories as well as lower mean distress caused by experienced involuntary memories than $\mathrm{NC}$ women.

The second aim was to confirm trait rumination, specifically trait brooding, as a vulnerability factor for greater involuntary recall and distress following a trauma analogue film. Trait rumination shares a positive relationship with frequency of involuntary recall following stressor exposure. Because of this, it was hypothesized that women reporting higher trait brooding scores would also report increased mean frequency of involuntary memories after exposure to the trauma analogue film above and beyond any reported depressive symptoms. Women with higher trait brooding scores were also hypothesized to experience higher levels of distress as a result of involuntary recall.

The third aim was to examine the interaction of these potential sex-linked vulnerabilities. Though both hormonal status and rumination are associated with amygdala activation (Andreano \& Cahill, 2010; Bayer et al., 2014; Goldstein et al., 2005; Petersen \& Cahill, 2014), and potentially lend themselves to sex-specific pathways to involuntary memory development after stress exposure, they have not been previously studied together. Thus, this study addressed this gap. It was hypothesized that NC women reporting more frequent brooding rumination would experience the greatest frequency of involuntary memories related to the film as well as the greatest distress as a result of this recall. Those reporting hormonal contraceptive use and reporting lower levels of brooding rumination were hypothesized to report the lowest frequency of involuntary memories as well as the lowest distress in response to these memories. 
In addition to involuntary memory frequency and related distress, interference in current activity due to involuntary memories was also examined. To our knowledge, this has never been studied. Thus, there were no hypotheses regarding how hormonal status and trait rumination were related to reported interference. 


\section{GENERAL METHOD}

\section{Study Design}

The originally proposed study design involved comparing three distinct hormonal status groups on involuntary memory characteristics over one week following exposure to a trauma analogue film. The groups consisted of combined hormonal contraceptive users, $\mathrm{NC}$ women in the follicular phase and $\mathrm{NC}$ women in the luteal phase. $\mathrm{NC}$ women came into the lab while menstruating and were randomized into either the follicular or luteal phase group. Women randomized into the follicular phase then completed all study procedures during the same appointment, while those randomized into the luteal phase were given an ovulation testing kit. Once ovulation was detected during home testing, women were scheduled to come back to the lab and complete the remaining study procedures. After multiple months of data collection, it was determined that this study would require over two years of participant recruitment before it could be completed. This was mainly due to difficulties related to necessary visit timing and scheduling that arose when recruiting and retaining eligible naturally cycling women. Thus due to feasibility, the study was amended to instead compare two hormonal status groups, combined hormonal contraceptive users and $\mathrm{NC}$ women at any point in their cycle. 


\section{Participant Recruitment and Compensation}

Participants were recruited from the University of Louisville and broader

Louisville community through the use of flyers and digital advertising. Advertisements targeted either NC women or combined contraceptive users. Participants could choose to receive either 2.5 research credits or a $\$ 25$ gift card as compensation for their participation.

\section{Eligibility}

Hormonal status. Women reporting regular menstrual cycles lasting between 2332 days were eligible for participation in this study. In the NC group, those who were pregnant or using hormonal contraceptives in the last three months or those who were currently breastfeeding were excluded due to the impact each experience has on one's hormonal milieu. In the hormonal contraceptive group, women must have been using a combined hormonal contraceptive method for at least a month in order to be eligible for the study.

Ethical considerations. Those currently receiving or those that have ever received psychological treatment for a diagnosed psychological disorder were excluded due to the nature of the stimuli and our goal to cause acute distress. Additionally, those who reported having experienced a serious car accident where someone could have been killed or seriously harmed or those who have had someone close to them die or be seriously injured in a car accident were also excluded.

Other considerations. Daily access to the internet was required for eligibility. 


\section{Procedure}

Laboratory visit. Eligible participants came to the lab to be consented at any time during their cycle. Demographic information was obtained and participants were asked about current contraceptive use, contraceptive and menstrual cycle history, trait rumination, and lifetime history of exposure to serious car accidents. Collected information was reviewed by the experimenter for eligibility to continue in the study.

Participants were then fitted with a blood pressure cuff and told to relax and silently name the colors that appeared on the screen. A slide show of different colored rectangles was then shown for ten minutes in order to neutralize intense negative or positive affect. Following this task, participants were asked to rate how they currently felt. After reporting on state affect, participants were instructed to view the upcoming film as if they were an actual witness to each scene, fully experiencing their emotion (cf. Soni et al., 2013). A trauma analogue film, lasting approximately 15 minutes, was then shown. After film exposure, participants again reported on state affect and also reported on attention paid to the film.

Current distress due to film exposure was assessed at the end of this visit on a scale from 0-100. Participants reporting continued distress (50 or greater) were given time to lower their distress levels before leaving the lab. Distress ratings below 50 indicated that the participant was ready to leave the lab. Participants were then asked about the email address they preferred to use for the follow-up surveys. Lastly, they were told that they should receive their first email that evening, and to call the lab or email the investigator if they had any problems completing the study. 
Daily follow-up phase. Participants were followed for seven days using Survey Monkey. An email invitation to complete that day's follow-up survey was sent every evening around $7 \mathrm{pm}$. Participants reported on involuntary memories related to the trauma analogue film. The final survey ended by thanking the participants for their participation, giving the participants a list of local resources in case they desired to seek assistance for anything experienced during the course of the study, and again provided contact information for the lab in case there were any lingering questions or concerns. One participant did request to be contacted and informed of the study results upon study completion and data analysis.

\section{Materials and Measures}

Demographics and hormonal information. Participants answered questions about their

age, ethnicity, family income, tobacco use, whether they were currently a student, whether they currently worked, and if so, what shift they worked. Participants were asked whether they were currently using a hormonal contraceptive and if so, whether the contraceptive was combined or progestin only in formulation. Women were additionally asked about whether their menstrual cycle was regular, how many days it typically lasted, what the first day of their current menstrual cycle was and when they expect to begin their next cycle. Hormonal status was dummy coded using hormonal contraceptive (HC) use as the reference category (e.g., $1=\mathrm{HC}, 0=\mathrm{NC})$.

Ruminative response scale (RRS). The Ruminative Response Scale is a 10-item measure of trait rumination comprising two factors, brooding and reflection. This measure does not use items confounded by symptoms of depression (Treynor et al., 
2003). Participants responded to items (e.g., "think 'Why do I always act this way?”) given what is typical for them. Responses range from 1 (almost never) to 4 (almost always). The brooding rumination subscale was used in this investigation. The brooding subscale is reported to have a Cronbach's alpha of 0.77 and demonstrates good stability over one year $(r=0.62)$. Cronbach's alpha was 0.84 for entire measure, 0.70 for the brooding items, and 0.82 for reflection items in the current study.

Patient health questionnaire-9 (PHQ-9). The PHQ-9 (Kroenke, Spitzer, \& Williams, 2001) is a 9-item depression screening tool. Participants responded to items (e.g., poor appetite or over-eating) describing how frequently they experienced each symptom over the last two weeks. Responses range from 0 (not at all) to 3 (nearly every day). Reliability of the PHQ-9 is adequate with a Cronbach's alpha ranging from 0.86 to 0.89. Cronbach's alpha was 0.70 for the current study. Acute reliability is also high, with a correlation of 0.84 between two administrations over 48 hours.

Penn state worry questionnaire (PSWQ). The Penn State Worry Questionnaire (Meyer, Miller, Metzger, \& Borkovec, 1990) is the most common self-report measure used to examine worry. The PSWQ has high internal consistency and good test-retest reliability (Meyer et al., 1990). Cronbach's alpha for the current study was 0.94. Participants rated 16 items (e.g., "My worries overwhelm me.") on a scale of 1 (not at all typical of me) to 5 (very typical of me).

DSM-5 self-rated level 1 cross-cutting symptom measure-adult. The DSM-5 Self-Rated Level 1 Cross-Cutting Symptom Measure-Adult (American Psychiatric Association, 2013) measures 13 clinically relevant domains (i.e. depression, anger, mania, anxiety, somatic symptoms, suicidal ideation, psychosis, sleep problems, memory, 
repetitive thoughts and behaviors, dissociation, personality functioning, and substance use) present across disorders. This measure was included to measure and describe any broad domains of psychopathology present in the current sample. The measure was seen to be clinically useful and demonstrated good test-retest reliability in Canadian and U.S. adult clinical samples in DSM Field Trials (American Psychiatric Association, 2013). Participants responded to 23 items (e.g., "Problems with sleep that affected your sleep quality over all?") using a scale of 0 (not at all) to 4 (nearly every day) in regards to what they experienced over the last two weeks. Because it was likely that a large portion of our sample would be under the age of 21 , an item asking about drinking was not included.

Life stressor checklist-revised (LSC-R). Three items from the LSC-R (Wolfe \& Kimerling, 1997), a 30-item checklist of stressful and potentially traumatic events occurring over a lifetime, were administered. These items were used to a) screen for those who have directly experienced a car accident that could have resulted in death or serious injury, b) screen for those who had a loved one that died or was seriously injured in a car accident, and c) to determine whether participants using combined hormonal contraceptives and $\mathrm{NC}$ participants differed in experiences of having witnessed serious car accidents.

Measure of violent media consumption. Four items were used to estimate the average amount of time spent consuming violent video games and/or television programs (Fikkers, Piotrowski, \& Valkenburg, 2017). Participants reported how many days they typically consumed violent video games and how many days they typically consumed violent television programs during a week. Participants then reported how much time in hours they typically spent consuming this media on the days they reported. These 
answers were multiplied to yield an average amount of time in hours spent consuming violent video games and an average amount of time in hours spent consuming violent television programs per week. Items were shown to demonstrate adequate test-retest reliability (Video games: $r=.73$; TV: $r=.51$ ) and criterion validity (Video games: $r=$ $.43 ; \mathrm{TV}: r=.18)$ in this same study.

Positive and negative affect scale (PANAS). The PANAS (Watson, Clark, \& Tellegen, 1988) is a 20-item measure of state affect. This measure contains ten positive and ten negative affective words. Participants are to respond to these words by reporting how they currently feel (1-very slightly or not at all to 5-extremely). The PANAS demonstrates adequate consistency and reliability with Cronbach's alpha ranging from 0.86 to $0.90(r=0.68)$ for positive and from 0.84 to $0.87(r=0.71)$ for negative affect items. For the present investigation, Cronbach's alpha was 0.91 for the ten positive items and 0.66 for the ten negative items pre-film administration. Cronbach's alpha was 0.88 for both the positive and negative items post-film administration.

Trauma analogue film. This investigation utilized a 15-minute highway safety film containing graphic footage of car accidents, severe injuries, and resulting fatalities. Though this type of footage is frequently used in trauma analogue film paradigms (Holmes \& Bourne, 2008; James et al., 2016), this specific film has not previously been used for this purpose. This film also included short interviews with loved ones of those who died in the accidents shown.

Attention paid to the film. Participants rated how much attention they paid to the trauma analogue film, using a scale ranging from 0 (no attention at all) to 10 (complete attention) (cf. Holmes et al., 2004; Laposa \& Rector, 2012). Participants were also 
recorded while they watched the trauma analogue film and the experimenter recorded the amount of time that the participant looked away from the screen while viewing the film.

Time spent not looking at the screen was recorded by four different coders. Thus, this variable was first examined for inter-rater reliability. The PI coded most (84\%) film clips, and three additional experimenters coded 12 clips. In order to calculate inter-rater reliability, the PI then double-coded these 12 clips. One clip was unusable due to video equipment malfunction. Percent agreement for the remaining 11 clips was $37 \%$. This poor agreement is likely due to poor video quality and resulting difficulty determining where the participant's eyes were focused. In addition to poor video quality, it was relatively rare that an experimenter outside of the PI conducted the visit and thus coded the amount of time the participant spent looking away from the screen. Thus, poor agreement may also be due in part to the amount of practice or time having elapsed between chances given to code video. This was dependent on participants showing to their session and remaining eligible after being screened. Correlations were computed to determine the relationship between these two attention variables. Using the PI-only coded data, a weak negative correlation $\left(r_{s}=-0.27\right)$ was found. This was only slightly improved from the weak negative correlation $\left(r_{s}=-0.20\right)$ found when using data obtained from all four coders. However, because of the poor agreement between raters and the slight improvement in correlation between the two attention measures, only PI-coded ratings were used in all analysis.

Experience of intrusions scale (EIS). The Experience of Intrusion Scale (Salters-Pedneault, Vine, Mills, Park, \& Litz, 2009) is a validated five-item measure of the frequency, as well as the intensity of unwantedness, unpredictability, distress and 
interference caused by these memories in the last 24 hours. Participants responded (0almost never to 4-very frequently) to the frequency item and (0-not at all to 4-extremely) to all intensity items (e.g., "On average, how distressed were you when these thoughts came to mind?") given their experiences over the last 24 hours. Scoring of this measure involves summing each of the five items to form a total score. The validation study used a trauma analogue film paradigm and so this measure should be well-suited for this study. This measure demonstrates good consistency with Cronbach's alphas $>0.83$ over multiple administrations as well as good reliability $(r=.83-.90)$. Cronbach's alpha of the total score was 0.85 during this investigation. This measure also shows statistically significantly, positive correlations with PTSD re-experiencing and intrusion symptoms (Salters-Pedneault et al., 2009). For the current study, the frequency, involuntary memory related distress, and involuntary memory related interference items were used to test study aims.

\section{The perceived awareness of the research hypothesis scale (PARH). The} Perceived Awareness of the Research Hypothesis Scale (Rubin, 2016) is a four-item selfreport measure of demand characteristics and participant knowledge regarding research hypotheses. Participants rated (1-strongly disagree to 7- strongly agree) each item (e.g., "I knew what the researchers were investigating in this research.") according to how aware they believed they were. Cronbach's alpha has ranged from .76 (Milner, Wagner, \& Crouch, 2017) to .93 (Wang, Chen, Poon, Teng, \& Jin, 2017). Cronbach's alpha was 0.69 in this study.

Cardiovascular reactivity. Systolic blood pressure (SBP), diastolic blood pressure (DBP) and heart rate (HR) were collected using a Dinamap 8100 monitor 
(Dinamap XL/Pro 100). Two readings were taken during the baseline phase (at five and 10 minutes) and two readings were taken during the trauma analogue film (at 55 seconds and at $12 \frac{1}{2}$ minutes). Readings were averaged to form baseline and trauma analogue film scores.

Other measurement. During follow-up, participants were asked about how many hours they spent in a vehicle that day as well as the amount of miles they traveled. These items were asked in order to determine that participants in the hormonal status groups did not statistically significantly differ in either, potentially confounding results given that cars and driving may be a memory cue following film exposure.

\section{Data Analytic Strategy}

To inform recruitment and determine the sample size needed for analysis, an $a$ priori power analysis was conducted. Power tests were completed using calculations based on Green (1991) to determine sample sizes necessary to detect relationships of interest. This formula $\left(N \geq\left(8 / f^{2}\right)+(m-1)\right)$ uses the effect size $\left(f^{2}\right)$ as well as the proposed number of predictors $(m)$ to help calculate the necessary sample size (Tabachnick $\&$ Fidell, 2013). This calculation supported a necessary sample size of 57 to test study aims one and two. It was estimated that aim 3 would require a sample size of approximately 103.

Data were examined for missing data, and some missing follow-up and questionnaire data were seen, some due to experimenter error. Not all demographic items were included when the study began and because of this, twenty-five percent of the sample $(n=19)$ were missing age, level of education, employment status, and student status information. Additionally, one participant gave their age, but did not report on 
these other demographic items. Another four participants did not answer all cross-cutting symptom measure items; these missing data points ultimately resulted in up to two missing scores per subscale. Experimenters were unable to obtain full cardiovascular data on nine participants, leaving 68 participants with complete cardiovascular data. Lastly, a number of follow-up data points were missing for various participants on various days or were completed on the wrong day over the seven day follow-up and thus were not included in analysis. Of the 77 total participants, 35 (45\%) had complete follow-up data completed on the correct days, $12(16 \%)$ had one day of missing follow-up data, three (4\%) were missing two days of follow-up data, 14 (18\%) were missing three days, six (8\%) were missing four days, two were missing five days (3\%), four were missing six days (5\%), and one participant did not complete any of their follow-up surveys on the correct day (1\%). Little's Missing Completely at Random Test was used to determine if there was a distinguishable pattern in this missing follow-up data (Enders, 2010). It was determined that follow-up data were indeed missing completely at random $\left(X^{2}(282)=\right.$ $0.00, p=1.00)$, containing 22 unique patterns of missing follow-up data.

All continuous dependent variables were examined for normality separately within their respective hormonal status group (Tabachnick \& Fidell, 2013). Available daily ratings for involuntary memory frequency, distress, and interference were averaged across all available daily assessments before being assessed. When a variable was found to violate normality, transformations were attempted. Due to wide variability in how effective these transformations were in correcting descriptive variables, when these variables were found to violate normality, nonparametric tests were used. Mean frequency, resulting distress, and mean total frequency and intensity of involuntary 
memories were all square root transformed. Mean interference in current activity caused by involuntary memories was inverse transformed, but remained skewed. The transformed variable was used in analysis, but these results should be interpreted cautiously.

The cross-cutting symptom measure's subscales were all positively skewed due to the number of participants reporting no symptoms in each domain. Many of these subscales remained skewed following transformation and so each subscale was dichotomized as having notable symptoms or not using thresholds determined through utilization of the measure's scoring guide (American Psychiatric Association, 2013). For each symptom domain, "mild" or greater symptoms were coded as notable symptoms (1), and no or "slight" symptoms were coded as no notable symptoms (0), with the exception of psychotic and substance use symptom domains. For these latter domains, those reporting "slight" or greater symptoms were coded as having notable symptoms (1).

Outliers, defined as Z-scores $>3.29$ or $<-3.29$ (Tabachnik \& Fidell, 2013), were observed in multiple dependent variables. Outliers were not found to be due to mistakes in data entry. In order to reduce their influence, outliers were replaced with the value of the next most extreme observation (Tabachnick \& Fidell, 2013).

For regression analyses, trait brooding scores were grand-mean centered before being used for analyses and interaction terms were created using these centered trait brooding values (Tabachnick \& Fidell, 2013). PHQ-9 total scores were also grand-mean centered before being used for regression analyses (Tabachnick \& Fidell, 2013). 
A correlation matrix was calculated to examine associations between variables of interest. Spearman correlation coefficients were calculated for this matrix due to nonnormality of variables used. No threats of multicollinearity were found (see Table 1). 


\section{RESULTS}

\section{Sample}

Ultimately, 140 participants were consented into the study, 77 progressed to the follow-up and 76 participants submitted some useable follow-up data. Of the 140 women consented into the study, 54 were ineligible (15 had a loved one involved in a serious accident, 11 used progestin only contraceptives, eight reported current either being bothered by thoughts that they would be better off dead or of hurting themselves in some way or bothered by thoughts of actually hurting themselves over the past two weeks, eight reported past psychological treatment, five reported an irregular cycle, four had been in a serious car accident themselves, and three had stopped taking their hormonal contraceptive within the last three months). In addition, nine eligible participants did not complete the entire laboratory portion of the study. One participant was unable to watch the entire trauma analogue film due to emotional distress, and the other eight women did not return to complete the laboratory portion after receiving an ovulation testing kit. These eight women were recruited as a part of the original protocol. Of the 140 participants consented into this study, 77 (43 combined hormonal contraceptive users and $34 \mathrm{NC}$ ) were eligible, completed all lab portions of the study, and were sent follow-up survey invitations every evening for seven days. This sample of 77 participants primarily consisted of white $(64.94 \%)$ college-students (96.49\%) between 18-34 (Mdn=20.00, 
$I Q R=2.00)$ years-old, who have never smoked cigarettes $(65 \%)$ and that reportedly had some confidence that they knew something about the study hypotheses $(M=15.78, S D=$ 4.50).

T-tests and chi-square tests (or Mann-Whitney U and Fisher's Exact tests) were used to test group differences in continuous and categorical variables. The only variable found to significantly differ between the two groups was self-reported difficulty with sleep. A Fisher's Exact test showed that combined hormonal contraceptive users reported greater problems with sleep that affected their sleep quality overall when compared to naturally cycling women $(p<0.01, O R=0.12,95 \% C I=0.02-0.56$; See Table 2$)$.

\section{Psychopathology, Rumination, and Worry}

The current sample reported low levels of psychopathology (See Table 3).

Reported depressive symptoms $(M d n=3.00 ; I Q R=3.00)$, rumination $(M d n=16.00 ; I Q R$ $=7.00)$, and specifically brooding rumination $(M d n=8 ; I Q R=3)$ were all reported at low levels. Using an cutoff of 8 or higher on the PHQ-9 (Manea, Gilbody, \& McMillan, 2012), two hormonal contraceptive users and three NC participants met criteria for probable depression. Worry on average was reported at a moderate $(M=46.67, S D=$ 14.88) level. Using a cutoff of 45 or higher (Behar, Alcaine, Zuellig, \& Borkovec, 2003), 23 hormonal contraceptive users and $17 \mathrm{NC}$ participants met criteria for probable generalized anxiety disorder. Relatedly, notable symptoms of anxiety were the most commonly $(28.57 \%$ ) reported symptom domain in this sample, with sleep difficulties being the second most $(22.08 \%)$ reported symptom. Psychosis, memory problems, and repetitive thoughts were the symptom domains reported by the fewest participants at one individual each. 


\section{Responses to the Film}

Attention. Subjectively, participants reported paying a high level of attention to the film $(M d n=10, I Q R=0.50)$ and a Mann Whitney $\mathrm{U}$ test showed no statistically significant differences between the hormonal status groups. No participant was excluded from analysis due to a subjective report of low attention.

On average, participants spent between nine and 10 seconds $(M d n=4, I Q R=10)$ not looking at the screen. A Mann Whitney U test demonstrated no statistically significant differences between the hormonal status groups (See Table 4).

Affective response. State negative and positive affect were assessed using a series of two 2 (Group [Hormonal contraceptive users/NC]) x 2 (Time [pre-film/postfilm]) ANOVAs with repeated measures on Time. As expected, this analysis revealed a main effect of Time for negative affect $\left(F(1,75)=218.74, p<0.01, \eta^{2}=0.74\right)$, where negative affect was higher following film exposure then before film exposure. There were no other statistically significant effects displayed for negative or positive affect (see Table 4).

Cardiovascular response. Cardiovascular responses (SBP, DBP, HR) were assessed using a series of three 2 (Group [Hormonal contraceptive users/NC]) x 2 (Time [pre-film/post-film]) ANOVAs with repeated measures on Time. No statistically significant effects were revealed, however a trend $\left(F(1,67)=3.36, \mathrm{p}<0.07, \eta^{2}=0.05\right)$ for a main effect of Time was found when examining DBP, demonstrating higher values following film exposure. No other statistically significant effects were revealed (See Table 4). 


\section{Involuntary Memories: Frequency, Distress, and Interference with Activity as a Product of the Trauma Analogue Film}

Average scores on involuntary memory characteristics items generally decreased over the study's seven day period (See Figures 2-5). Frequency decreased from a median of $2.00(I Q R=1.50)$ to a median of $0.00(I Q R=1)$, distress from a median of $2.00(I Q R$ $=1.00)$ to a median of $0.00(I Q R=1.00)$, and interference level from a median of 0.00 $(I Q R=1.00)$ to $0.00(I Q R=0.00)$. Participants reported a median combined total intensity and frequency score of involuntary memory of $3.31(I Q R=4.68)$ across the week. Involuntary memory frequency and intensity also generally decreased over the seven days of follow-up, with a median score of $8.00(I Q R=6.00)$ on day 1 and a median score of $0.00(I Q R=5.00)$ on day 7 .

\section{Hormonal Status, Trait Brooding Rumination, and Involuntary Memory}

Three separate hierarchical linear regression models were used to test hypothesized associations between hormonal status and brooding rumination, and frequency of involuntary memories, distress experienced as a result of memories, and interference with daily activities experienced as a result of involuntary recall. Depression symptom severity was adjusted for by being entered into step one of each regression model. Dummy coded hormonal status and trait brooding rumination were entered into the second step of each regression model to test for main effects (proposal aims 1 and 2). The interaction term was then entered into step 3 to test proposal aim 3. Statistically significant product terms (i.e., interactions) were further examined through the use of simple slopes analysis. 
Frequency. As shown in Table 5, depression symptom severity was a statistically significant predictor of involuntary memory frequency at each step. There were no other statistically significant effects.

Distress. As shown in Table 6, depression symptom severity was a statistically significant predictor of distress as a result of involuntary memory at each step. There were no other statistically significant effects.

Interference. As shown in Table 7, no statistically significant predictors were found.

\section{Ancillary Analyses}

\section{Combined total frequency and intensity of involuntary memories. An}

additional hierarchical regression analysis was conducted to examine hormonal status and brooding rumination as predictors of combined total frequency and intensity of involuntary memories (i.e., mean EIS score). As shown in Table 8, depression severity was a statistically significant predictor of combined total frequency and intensity of involuntary memories at each step. No other statistically significant predictors were observed.

Three hormonal status groups. Finally, all proposed and ancillary regressions were also completed using three hormonal status groups after dividing the $\mathrm{NC}$ group into women likely to be in the follicular $(n=16)$ or luteal $(n=18)$ phase when exposed to the trauma analogue film. This was done by first placing those randomized into either the follicular or luteal phase into their respective group. For those that were not enrolled in the original study design, phase was estimated by using the participant's reported anticipated start of their next menstrual cycle and the date that they were exposed to the 
trauma analogue film. Those that were exposed to the trauma analogue film within 14 days of their next anticipated menstrual cycle start date were coded as members of the luteal phase group. All other women in the NC group were classified as follicular phase. Of note, two out of five women randomized into the luteal phase would have been grouped incorrectly using only their estimated next menstrual start date. Two dummy coded variables were created with follicular phase as the comparison group. Descriptives were also provided for each of the three hormonal status groups.

Involuntary memory frequency. Hormonal contraceptive users were found to demonstrate a median frequency score of $0.54(I Q R=1.12)$, follicular phase women demonstrated a median frequency of $0.77(I Q R=0.97)$, and luteal phase women demonstrated a median frequency score of $1.07(I Q R=1.27)$. As shown in Table 9, depression severity was a statistically significant predictor of mean involuntary memory frequency at each step. No other statistically significant predictors were determined.

Involuntary memory distress. Hormonal contraceptive users were found to demonstrate a median distress score of $0.57(I Q R=1.17)$, follicular phase women demonstrated a mean distress score of $0.71(I Q R=0.97)$, and luteal phase women demonstrated a median distress score of $1(I Q R=0.81)$. As shown in Table 10 , depression severity was a statistically significant predictor of distress resulting from involuntary memories at each step. No other statistically significant predictors were determined.

Involuntary memory interference. Hormonal contraceptive users were found to demonstrate a median interference score of $0.15(I Q R=0.50)$, follicular phase women demonstrated a median interference score of $0.23(I Q R=0.43)$, and luteal phase women 
demonstrated a median interference score of $0.07(I Q R=0.43)$. As shown in Table 11, no statistically significant predictors were found.

\section{Combined total frequency and intensity of involuntary memories. Hormonal}

contraceptive users were found to demonstrate a median combined total frequency and intensity of involuntary memories score of $2.00(I Q R=5.19)$, follicular phase women demonstrated a median combined total frequency and intensity of involuntary memories score of $3.43(I Q R=5.34)$, and luteal phase women demonstrated a median combined total frequency and intensity of involuntary memories score of $5(I Q R=4.29)$. As shown in Table 12, depression severity was a statistically significant predictor of combined total frequency and intensity of involuntary memories at each step. No other statistically significant predictors were determined. 


\section{DISCUSSION}

Women are diagnosed with PTSD at higher rates than men, a pattern not entirely accounted for by differences in experienced trauma type (Tolin \& Foa, 2006). Thus, explanations for this well-established difference in prevalence rate must lie elsewhere. The mnemonic model of PTSD suggests that probing variables impacting memory processes may help to better understand this difference in PTSD prevalence. Two sexlinked variables of interest in the current study were trait brooding rumination and hormonal status/contraceptive use. Both trait brooding rumination and hormonal contraceptive use have been positively associated with amygdala reactivity in previous literature, likely influencing memory modulation when exposed to aversive stimuli through enhanced amygdala reactivity.

The current study examined 77 (43 combined hormonal contraceptive users and $34 \mathrm{NC}$ ) women reporting varying levels of trait brooding rumination who were exposed to a trauma analogue film depicting scenes of serious car accidents and resulting casualties. Participants then completed seven separate follow-up surveys, assessing for aspects of involuntary memory frequency and intensity for seven days following exposure to the film. Contrary to predictions, trait brooding and hormonal contraceptive status were not statistically significant predictors of involuntary memory frequency nor of distress or interference caused by involuntary memory. 
Participants' responses to the film in the current study involved both anticipated and unanticipated reactions. Attention paid to the film was high in the current study which is beneficial if the desired outcome is to produce involuntary memories of the film because one must attend to stimuli in order to remember them. Negative affect showed statistically significantly increases following exposure to the trauma analogue film. Though the current study found expected increases in negative affect, changes in cardiovascular measures were not demonstrated. Typically, a reduction in heart rate has been associated with increased involuntary memories when viewing this kind of film (Arnaudova \& Hagenaars, 2017; Chou, Marca, Steptoe, \& Brewin, 2014; Holmes, Brewin, \& Hennessy, 2004), however statistically significant differences between preand post-film cardiovascular measures were not found in the present study. This lack of cardiovascular reactivity suggests that our sample may either be more resilient than those examined in past research or that our sample was not sufficiently activated by the trauma analogue film used in this study.

Further complications may have arisen due to the particular film chosen to be used as the trauma analogue film in the current study. This specific film has not previously been used as a trauma analogue film in prior research, but was chosen for the current study due to similarities in content it shares with previously utilized trauma analogue films. Like previously used films, the current film showed graphic scenes of car accidents and resulting casualties. Also like other films, the current film showed a variety of car accidents. In the film used for the current study, loved ones of the deceased provided context to the scenes, talking about the accident and/or their loved ones. This likely differed from the majority of previously used films, but was seen as a strength due 
to the increased context helping to enhance the negative affect experienced. In fact, this study demonstrated a larger effect size than previous research when examining change in negative affect from pre- to post-film. However, it may be that previous films provided a greater number of graphic scenes, providing more material for involuntary memories following exposure. Not all trauma analogue films depict car accidents. In fact, a number of trauma analogue film studies use films depicting sexual assault rather than car accidents. This material may be particularly disturbing to female participants and so it may be that the film used in the current study was less impactful than films used in previous research. Of note, negative films depicting sexual content and negative films depicting traffic content have not been shown to produce statistically significantly differences in the frequency of intrusions experienced after exposure (Arnaudova \& Hagenaars, 2017).

A known complication occurred in recruitment and grouping based on hormonal status. Feasibility did not allow for the recruitment of three distinct hormonal status groups and thus current findings may have been impacted by the necessary merging of the two naturally cycling groups. Three distinct hormonal status groups were first proposed due to differences in hormonal milieu throughout a typical cycle, specifically differences in progesterone levels. Women randomized into the follicular phase were to be exposed to the film during menses, when both estrogen and progesterone are low. Women randomized into the luteal phase were to be exposed to the film following ovulation, when progesterone levels surpass estrogen levels and reach their peak. Because of the distinct differences in hormonal milieu between these two groups, allowing women to take part in the study at any point during their cycle may have 
impacted the ability to find a main effect of hormonal group in this study. Effects were probed using the original three groups, but group membership was estimated using the self-reported cycle information provided by each participant rather than using ovulation and menses as objective markers of cycle phase. This method of post-recruitment group assignment is far less precise than using objective hormonal markers to determine cycle phase. Thus, participants may have been grouped incorrectly. Indeed, two out of the five women enrolled in the study using the original methodology and randomized into the luteal phase group reported an incorrect first day of their next menses. These women would have been grouped incorrectly had they not tested for ovulation in order to more precisely determine when they entered the luteal phase.

Another potential reason for lack of support for hypotheses would be the use of the EIS to measures involuntary memories in the current study. This specific measure was not used in any of the previously discussed literature. The EIS measures frequency and intensity of different characteristics of involuntary memories on a Likert scale, but does not obtain an estimated count. Most of the cited studies used an estimated diary count of intrusions experienced over the follow-up period and some waited until the participants came in for their final laboratory visit before asking for retrospective recall of their experience with involuntary memories. While having a similar goal, these studies ultimately used a different outcome measure to measure the same construct. While one could argue that the use of the EIS improves upon diary methods or retrospective recall over multiple days, this difference in outcome measurement used may contribute to discrepancies in current study findings and previous research. 
In addition to the EIS being a wholly different method for measuring involuntary memories as an outcome, the current results of the EIS differed from results achieved in the original method paper. As expected, the EIS mean score was highest on the first day and decreased over time, similar to the original paper. However average total score for each day in the current study fell well below the means obtained in the original EIS method paper (Salters-Pedneault et al., 2009). Salters-Pedneault and colleagues found the combined total frequency and intensity of involuntary memories score for day one to be 12.19 , while the current study found a combined total frequency and intensity of involuntary memories score of 7.15 on day one. This supports that idea that there are either additional differences in sample characteristics or that there is a difference in trauma analogue film stimulus that led to fewer distressing involuntary memories in the current study. Of note, the original validation study used a trauma analogue film that depicted a sexual assault.

In terms of differences in sample, there may be variables that were either not measured or not of specific interest in the current study that interact with hormonal status and/or brooding rumination in order to produce the anticipated outcome. For example, hormonal contraceptive using women with mineralocorticoid receptor haplotype two have been found to be less affectively impacted by aversive stimuli when compared to women with haplotype one or three (Hamstra et al., 2016). Combined hormonal contraceptives additionally vary in the generation of progestin used in formulation, with older generations having more androgenic effects than more recent generations. Thus, further parsing combined hormonal contraceptive user by the progestin used in their current contraceptive formulation may provide further insight into variation in findings. 
Studies investigating the impact of hormonal contraceptives on involuntary memories following stressor exposure are few in number and much is left to understand, especially as a recent study found that women who used any variety of hormonal contraceptive both rated aversive images as more emotional and demonstrated better recall of these images 10 minutes following presentation than women not using a hormonal contraceptive (Spalek et al., 2019). In addition, tobacco use may account for some portion of the discrepancy found between the current study findings and past research. Though only two participants reported current tobacco use, both women were combined hormonal contraceptive users. At least one study has found that nicotine may increase the number of intrusions experienced in those endorsing low levels of trait brooding rumination (Hawkins \& Cougle, 2013). Thus, it is possible that tobacco use may have increased involuntary memories in the combined hormonal contraceptive group, interfering with the ability to find main effects.

Depression symptom severity showed statistically significantly associations with involuntary memory frequency, related distress, and mean total frequency and intensity of involuntary memories in the current study. This was not unexpected, as a recent systematic review examining predictors of involuntary memories noted the consistency of the literature surrounding prior psychopathology, specifically depression symptom severity, and the positive relationship it shares with involuntary memory development (Marks, Franklin, \& Zoellner, 2018). A meta-analysis examining trauma analogue film studies also found depression symptom severity to be positively associated with involuntary memories following film exposure (Clark, Mackay, \& Holmes, 2015). Though brooding rumination and depressive symptoms do share a relationship, adjusting 
for depression symptom severity in the current study was not found to sufficiently explain why trait brooding rumination did not predict subsequent involuntary memory frequency or other involuntary memory characteristics. That is, no statistically significant zero-order correlations were observed between brooding rumination and memory characteristics in the present study. The rumination measure used in the present study excludes items shown to be confounded with depressive symptoms and the current study used only the trait brooding subscale. In contrast, a total rumination score is often used in studies of involuntary memories, rather than parsing out brooding (Smets et al., 2012). Past research on involuntary memory has also used a variety of measures to describe rumination that may or may not include items confounded with symptoms of depression (Kubota et al., 2014; Watkins, 2004). Additionally, the relationship and the direction of effects are unclear. Depressive symptoms have been argued in some research to partially mediate the relationship between rumination and involuntary memories (Smets et al., 2012) while other research argues that rumination mediates the relationship between depressed mood and involuntary memories (Kubota et al., 2014). Thus, conclusive evidence does not exist to state whether the true vulnerability may be brooding rumination, an aspect of rumination not described as brooding rumination, or an aspect of depressive symptoms not overlapping with trait brooding rumination.

Findings of the current study should be interpreted within the context of the study's limitations. Though studying phenomena following exposure to a traumatic event, the trauma analogue film differs from a real-life traumatic event in multiple ways: the stimuli provides no real threat to the participant, it lacks personal relevance to the participant, and it is expected. Those with personal experience or who have had a loved 
one involved in a serious accident were excluded. Participants who enrolled in this study were aware of the trauma analogue film and that it depicted scenes of serious car accidents and resulting casualties and still opted to participate. There may be personality variables that impact one's willingness to participate in a study like this that are not being accounted for. Additionally, though strengthening the study by attempting to control for the influence of experienced psychopathology on the development of involuntary memories following a trauma analogue film and minimizing the potential for participant distress, excluding those with any psychological or psychiatric treatment history limits the generalizability of the study findings. Experiencing psychiatric symptoms and/or meeting criteria for a diagnosable disorder is not rare (Steel et al., 2014). Because of this, our sample may be unusually healthy and may utilize additional coping strategies that impacted study findings. Compliance, though similar to previous research, is also a concern given the collection of seven points of follow-up data in this study.

Despite noted limitations, current study findings contain implications for both theory and practice. Study findings suggest that current depressive symptoms are more influential than trait brooding rumination or hormonal status when predicting involuntary memories and related distress following stressor exposure. Findings also bolster past research demonstrating that those experiencing depressive symptoms may be at greater risk for developing involuntary memories following stressor exposure. Implications for clinical practice include a rationale for focusing on the treatment of depressive symptoms, particularly when the patient frequently comes into contact with potentially traumatic events (e.g., as a part of their job) even if the individual may not meet full criteria for a current depressive episode. Future research has the opportunity to examine 
some of these possibilities and to strengthen the related literature. Comparisons of diary count methods and the EIS could be beneficial in determining the best method of capturing involuntary memory phenomena. In addition, more consistency in the trauma analogue film used in future work would also help to standardize the procedure and clarify discrepant findings. Much of the research on this topic has been done using participants with no or little known psychopathology, and so using larger and more varied samples could be helpful in making steps towards being able to generalize study findings to the broader population. Because psychopathology does impact this outcome, rather than exclude participants, measuring domains of psychopathology and controlling for this would be ideal. Once clear vulnerabilities to development of involuntary memories are clarified, future work should focus on the processes by which involuntary memories are maintained. While understanding what helps to produce distressing involuntary memory is necessary, involuntary memory of the event is common after exposure to a stressful event. It is when we determine what helps to maintain this phenomena over longer periods of time that we begin to truly study a pathological response to stress. Because of this, more longitudinal studies are needed that examine these outcomes over a significant period of time.

In conclusion, this study aimed to examine two potential sex-linked variables that might impact the experience of involuntary memories following stressor exposure. However, these variables were not found to predict involuntary memory frequency, related distress, or related interference. The only statistically significant predictor in this study was determined to be depression symptom severity. Findings of the current study highlight the potential importance of researching the proactive treatment of depressive 
symptoms, as they may related to developing involuntary memories following a stressor. Treatment of these symptoms may reduce one's vulnerability to experiencing involuntary memories following stressor exposure. Additional research is needed to fully understand differences in PTSD prevalence between men and women as well as what may make women more vulnerable to symptom development following a traumatic event. With this knowledge, better prevention and treatment measures can be developed to narrow this gap. 
Figure 1.

Comparison of hormone levels in naturally cycling women compared to those taking combined oral contraceptives

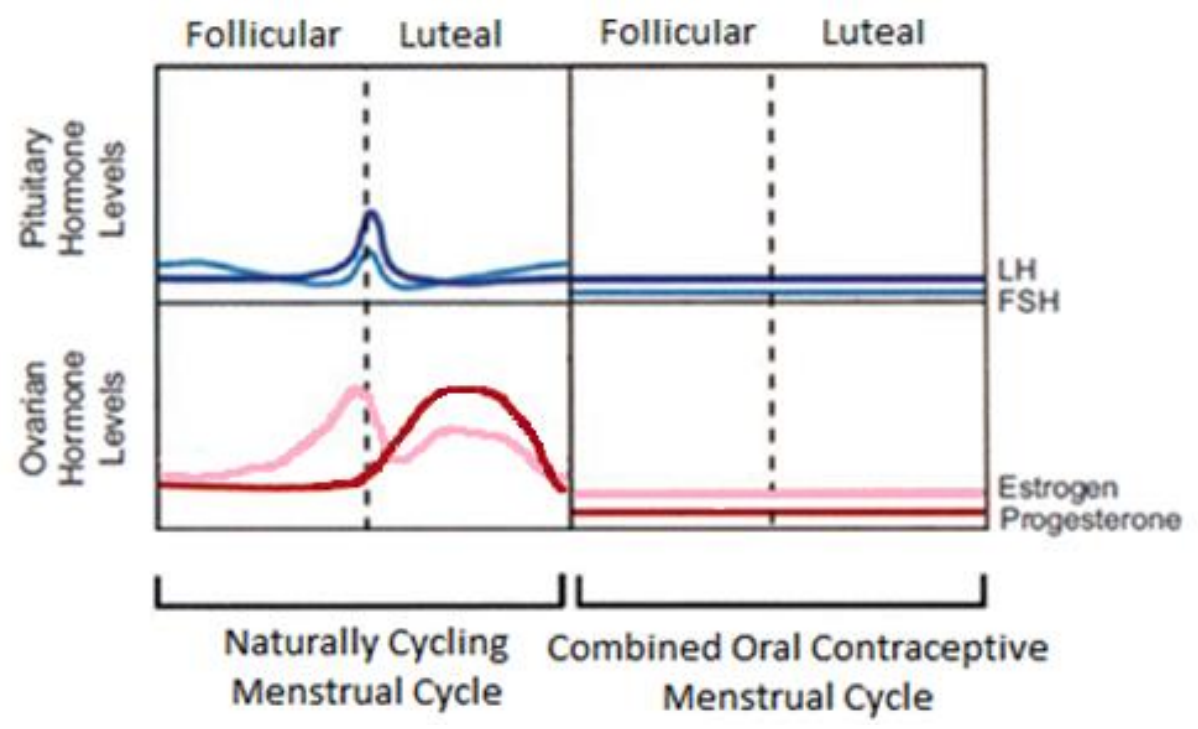

Note: Figure is adapted from Fleischman, D.S., Navarrete, C.D., \& Fessler, D.M.T. (2010). Oral Contraceptives Suppress Ovarian Hormone Production. Psychological Science 21(5):750-52 who adapted from The Benefits and Risks of Oral Contraceptives Today (1st ed., p. 12), by J. Drife, 1996, Pearl River, NY: Parthenon Publishing Group. Copyright 1996 by Parthenon Publishing Group. 
Table 1

Zero-Order spearman correlations for self-report variables used in hierarchical regressions

\begin{tabular}{|c|c|c|c|c|c|c|c|c|}
\hline & $\mathbf{1}$ & 2 & 3 & 4 & 5 & 6 & 7 & 8 \\
\hline 1. Depression & - & & & & & & & \\
\hline 2. Brooding Rumination & $0.53 * *$ & - & & & & & & \\
\hline 3. Hormonal Status & 0.05 & -0.06 & - & & & & & \\
\hline 4. Luteal & -0.08 & 0.04 & $-0.62 * *$ & - & & & & \\
\hline 5. Follicular & 0.02 & 0.04 & $-0.58 * *$ & $-0.28 *$ & - & & & \\
\hline 6. Frequency & $0.35 * *$ & 0.12 & -0.21 & 0.15 & 0.10 & - & & \\
\hline 7. Distress & $0.25^{*}$ & 0.10 & -0.09 & 0.05 & 0.06 & $0.81 * *$ & - & \\
\hline 8. Interference & 0.10 & $<-0.01$ & 0.03 & -0.07 & 0.04 & $0.51 * *$ & $0.74 * *$ & - \\
\hline $\begin{array}{l}\text { 9. Mean Experience of } \\
\text { Intrusions Scale }\end{array}$ & $0.24 *$ & 0.10 & -0.17 & 0.09 & 0.11 & $0.85 * *$ & $0.97 * *$ & $0.74 * *$ \\
\hline
\end{tabular}

Note. Frequency, Distress, Interference, and Mean Experience of Intrusions Scale $n=76$, all other variables $n=77$; Hormonal Status $(0=$ Naturally Cycling, $1=$ Hormonal Contraceptive Users); Luteal ( 1 $=$ Luteal, $0=$ Others $)$, Follicular $(1=$ Follicular, $0=$ Others $) ; *<.05 ; * *<.01$ 
Table 2

Sample descriptives

\begin{tabular}{|c|c|c|c|}
\hline Variable & $\begin{array}{c}\mathrm{HC} \\
(n=43)\end{array}$ & $\begin{array}{c}\mathrm{NC} \\
(n=34)\end{array}$ & $P$ \\
\hline Age (years) & $20.00(2.00)$ & $20.00(3.00)$ & 0.84 \\
\hline $\begin{array}{l}\text { Ethnicity } \\
\text { African American } \\
\text { Asian American } \\
\text { Caucasian } \\
\text { Latino or Hispanic } \\
\text { Biracial } \\
\text { Other }\end{array}$ & $\begin{aligned} 2 & (5 \%) \\
1 & (2 \%) \\
32 & (74 \%) \\
1 & (2 \%) \\
5 & (12 \%) \\
2 & (5 \%)\end{aligned}$ & $\begin{aligned} 9 & (26 \%) \\
2 & (6 \%) \\
18 & (53 \%) \\
2 & (6 \%) \\
2 & (6 \%) \\
1 & (3 \%)\end{aligned}$ & 0.08 \\
\hline $\begin{array}{l}\text { Income } \\
\begin{array}{l}0-9,999 \mathrm{k} \\
10,000-19,999 \mathrm{k} \\
20,000-29,999 \mathrm{k} \\
30,000-39,999 \mathrm{k} \\
40,000-49,999 \mathrm{k} \\
50,000-59,999 \mathrm{k} \\
60,000+\end{array}\end{array}$ & $\begin{array}{r}0(0 \%) \\
2(5 \%) \\
7(16 \%) \\
5(12 \%) \\
5(12 \%) \\
2(5 \%) \\
22(51 \%)\end{array}$ & $\begin{array}{r}1(3 \%) \\
2(6 \%) \\
4(12 \%) \\
6(18 \%) \\
4(12 \%) \\
4(12 \%) \\
13(38 \%)\end{array}$ & 0.68 \\
\hline $\begin{array}{l}\text { Education } \\
\qquad \begin{array}{l}\text { High School Degree or Equivalent } \\
\text { Some College but No Degree } \\
\text { Associate Degree } \\
\text { Bachelor Degree } \\
\text { Graduate Degree }\end{array}\end{array}$ & $\begin{aligned} 5 & (19 \%) \\
16 & (59 \%) \\
2 & (7 \%) \\
2 & (7 \%) \\
2 & (7 \%)\end{aligned}$ & $\begin{aligned} & 7(23 \%) \\
& 18(60 \%) \\
& 1(3 \%) \\
& 4(13 \%) \\
& 0(0 \%)\end{aligned}$ & 0.51 \\
\hline Violent TV (hours/week) & $2.00(5.00)$ & $2.00(4.50)$ & 0.78 \\
\hline Violent Games (hours/week) & $0.00(0.00)$ & $0.00(0.00)$ & 0.83 \\
\hline $\begin{array}{l}\text { Tobacco Use } \\
\text { Never } \\
\text { Irregular } \\
\text { Regular }\end{array}$ & $\begin{aligned} 27(63 \%) \\
14(33 \%) \\
2(5 \%)\end{aligned}$ & $\begin{array}{c}23(68 \%) \\
11(32 \%) \\
0(0 \%)\end{array}$ & 0.44 \\
\hline $\begin{array}{l}\text { Employment } \\
\text { Unemployed } \\
\text { Employed Part-time } \\
\text { Employed Full-time }\end{array}$ & $\begin{array}{r}6(22 \%) \\
17(63 \%) \\
4(15 \%)\end{array}$ & $\begin{array}{r}11(37 \%) \\
15(50 \%) \\
4(13 \%)\end{array}$ & 0.53 \\
\hline $\begin{array}{l}9 \mathrm{am}-5 \mathrm{pm} \\
3 \mathrm{pm}-11 \mathrm{pm} \\
11 \mathrm{pm}-7 \mathrm{am} \\
\text { Varies }\end{array}$ & $\begin{array}{l}15(35 \%) \\
8(19 \%) \\
1(2 \%) \\
8(19 \%)\end{array}$ & $\begin{aligned} 11 & (32 \%) \\
7 & (21 \%) \\
1 & (3 \%) \\
7 & (21 \%)\end{aligned}$ & 1.00 \\
\hline $\begin{array}{l}\text { Student } \\
\text { No } \\
\text { Yes }\end{array}$ & $\begin{array}{r}2(7 \%) \\
25(93 \%)\end{array}$ & $\begin{array}{r}0(0 \%) \\
30(100 \%)\end{array}$ & 0.22 \\
\hline $\begin{array}{l}\text { Saw Serious Accident } \\
\text { No } \\
\text { Yes }\end{array}$ & $\begin{array}{r}43(100 \%) \\
0(0 \%)\end{array}$ & $\begin{array}{r}34(100 \%) \\
0(0 \%)\end{array}$ & 0.63 \\
\hline $\begin{array}{l}\text { Average hours in a car over the past week } \\
\text { Average miles driven over the past week } \\
\text { Perceived Awareness of the Research } \\
\text { Hypothesis }\end{array}$ & $\begin{array}{r}1.31(1.54) \\
24.79(30.29) \\
15.14(4.30)\end{array}$ & $\begin{array}{r}1.00(1.64) \\
20.73(30.71) \\
16.53(4.67)\end{array}$ & $\begin{array}{l}0.49 \\
0.54 \\
0.20\end{array}$ \\
\hline
\end{tabular}


Table 3

Sample psychopathology, rumination, and worry

\begin{tabular}{lccc}
\hline \multicolumn{1}{c}{ Variable } & $\mathrm{HC}$ & $\mathrm{NC}$ & \\
& $(n=43)$ & $(n=34)$ & 0.57 \\
\hline Penn State Worry Questionnaire & $47.51(14.27)$ & $45.53(15.82)$ & \\
Cross-Cutting Domains & & & 0.69 \\
Depression & $3(7 \%)$ & $4(12 \%)$ & 1.00 \\
Anger & $5(12 \%)$ & $4(12 \%)$ & 0.63 \\
Mania & $7(16 \%)$ & $7(21 \%)$ & 0.88 \\
Anxiety & $12(28 \%)$ & $10(29 \%)$ & 0.65 \\
Somatic symptoms & $2(5 \%)$ & $3(9 \%)$ & 1.00 \\
Psychosis & $1(2 \%)$ & $0(0 \%)$ & 1.00 \\
Sleep problems & $15(35 \%)$ & $2(6 \%)$ & 0.44 \\
Memory & $1(2 \%)$ & $0(0 \%)$ & 1.00 \\
Repetitive thought & $0(0 \%)$ & $1(3 \%)$ & 0.17 \\
Dissociation & $1(2 \%)$ & $1(3 \%)$ & 1.00 \\
Personality & $3(7 \%)$ & $6(18 \%)$ & \\
Substance use & $5(12 \%)$ & $4(12 \%)$ & 0.31 \\
Ruminative Response Scale Total & & & 0.58 \\
Total & $15.00(7.00)$ & $17.00(9.00)$ & 0.28 \\
Brooding & $8.00(3.00)$ & $7.50(4.00)$ & 0.64 \\
Reflection & $8.00(5.00)$ & $9.00(6.00)$ & \\
Patient Health Questionnaire-9 & $3.00(3.00)$ & $2.00(3.00)$ & \\
\hline
\end{tabular}

Note. Mdn $(I Q R)$ are reported for all variables other than the Penn State Worry Questionnaire where $M$ $(S D)$ is reported; $n$ and \% of sample having reported notable symptoms are reported for each cross-cutting domain of psychopathology; $\mathrm{NC}=$ Naturally cycling; $\mathrm{HC}=$ Hormonal contraceptive users; ${ }^{*} p<.05 ; * * p<.01$ 
Table 4

Attention, state affect, and cardiovascular variables

\begin{tabular}{lcc}
\hline Variable & Pre-Film & Post-Film \\
\hline Self-rated attention & & \\
HC & - & $10.00(0.00)$ \\
NC & - & $10.00(1.00)$ \\
Time not looking at the screen (seconds) & - & $3.00(8.00)$ \\
HC & - & $5.00(10.00)$ \\
NC & & \\
Positive Affect & $25.00(11.00)$ & $18.00(5.00)$ \\
HC & $18.50(11.00)$ & $19.00(9.00)$ \\
NC & $12.00(3.00)$ & $19.00(9.00)$ \\
Negative Affect & $11.00(3.00)$ & $21.50(10.00)$ \\
HC & $107.50(13.75)$ & $106.50(12.50)$ \\
NC & $106.50(13.00)$ & $105.50(15.50)$ \\
Systolic blood pressure (mmHg) & $65.00(7.25)$ & $66.00(6.00)$ \\
HC & $62.50(8.50)$ & $64.50(8.50)$ \\
NC & & \\
Diastolic blood pressure (mmHg) & $80.00(10.25)$ & $80.50(10.00)$ \\
HC & $80.00(11.00)$ & $79.50(10.00)$ \\
NC & & \\
Heart rate (bpm) & & \\
HC & NC &
\end{tabular}

Note. NC=Naturally cycling; $\mathrm{HC}=$ Hormonal contraceptive users; $M d n$ and $I Q R$ are reported for all variables 
Table 5

Predicting involuntary memory frequency in HC users and $N C$ women $(N=76)$

\begin{tabular}{|c|c|c|c|}
\hline \multirow[b]{2}{*}{ Predictors } & \multicolumn{3}{|c|}{ Frequency } \\
\hline & Model 1 & Model 2 & Model 3 \\
\hline 1. Depression & $0.05 * *$ & $0.06^{* *}$ & $0.06^{*}$ \\
\hline 2. Brooding & - & -0.02 & $<-0.01$ \\
\hline Rumination & & & \\
\hline 3. Hormonal Status & - & -0.18 & -0.18 \\
\hline 4. Interaction $2 \times 3$ & - & - & -0.04 \\
\hline$R^{2}$ & $0.11 * *$ & $0.16^{* *}$ & $0.17 * *$ \\
\hline$\Delta R^{2}$ & - & 0.05 & 0.01 \\
\hline
\end{tabular}

Note. Values reported in this table are unstandardized regression weights $(b)$ unless otherwise labeled; Hormonal Status ( 0 = Naturally Cycling, $1=$ Hormonal Contraceptive Users); HC=Hormonal contraceptives; $\mathrm{NC}=$ Naturally cycling; ${ }^{*} p$ $<.05 ; * * p<.01$ 
Table 6

Predicting involuntary memory related distress in HC users and NC women $(N=76)$ Distress

\begin{tabular}{lccc}
\cline { 2 - 4 } \multicolumn{1}{c}{ Predictors } & Model 1 & Model 2 & Model 3 \\
\hline 1. Depression & $0.04^{*}$ & $0.05^{*}$ & $0.05^{*}$ \\
2. Brooding & - & -0.02 & $<-0.01$ \\
Rumination & - & -0.09 & -0.09 \\
3. Hormonal Status & - & - & -0.04 \\
4. Interaction 2x3 & $0.06^{*}$ & 0.08 & 0.09 \\
$\quad R^{2}$ & - & 0.02 & 0.01 \\
$\Delta R^{2}$ & & & \\
\hline
\end{tabular}

Note. Values reported in this table are unstandardized regression weights $(b)$ unless otherwise labeled; $\mathrm{HC}=$ Hormonal contraceptives; $\mathrm{NC}=$ Naturally cycling; Hormonal Status $(0=$ Naturally Cycling, $1=$ Hormonal Contraceptive Users $) ;{ }^{*} p<.05 ; * * p<.01$ 
Table 7

Predicting involuntary memory related interference in HC users and NC women $(N=76)$ Interference

\begin{tabular}{lccc}
\cline { 2 - 4 } \multicolumn{1}{c}{ Predictors } & Model 1 & Model 2 & Model 3 \\
\hline 1. Depression & -0.01 & -0.01 & -0.01 \\
2. Brooding Rumination & - & $<0.01$ & -0.01 \\
3. Hormonal Status & - & -0.01 & -0.01 \\
4. Interaction 2x3 & - & - & 0.02 \\
$R^{2}$ & 0.01 & 0.01 & 0.03 \\
$\Delta R^{2}$ & - & 0.00 & 0.02 \\
\hline
\end{tabular}

Note. Values reported in this table are unstandardized regression weights $(b)$ unless otherwise labeled; $\mathrm{HC}=$ Hormonal contraceptives; $\mathrm{NC}=$ Naturally cycling; Hormonal Status ( 0 = Naturally Cycling, $1=$ Hormonal Contraceptive Users $) ; * p<.05 ; * *<.01$ 
Table 8

Predicting combined total frequency and intensity of involuntary memories in HC users and NC women

\begin{tabular}{lccc}
\hline \multirow{2}{*}{ Predictors } & \multicolumn{3}{c}{ Mean } \\
\cline { 2 - 4 } & Model 1 & Model 2 & Model 3 \\
\hline 1. Depression & $0.08^{*}$ & $0.10^{*}$ & $0.10^{*}$ \\
2. Brooding Rumination & - & -0.04 & 0.02 \\
3. Hormonal Status & - & -0.35 & -0.35 \\
4. Interaction 2x3 & - & - & -0.11 \\
$R^{2}$ & $0.06^{*}$ & 0.10 & 0.12 \\
$\Delta R^{2}$ & - & 0.04 & 0.02 \\
\hline
\end{tabular}

Note. Values reported in this table are unstandardized regression weights $(b)$ unless otherwise labeled; $\mathrm{HC}=$ Hormonal contraceptives; $\mathrm{NC}=$ Naturally cycling; Hormonal Status ( 0 = Naturally Cycling, $1=$ Hormonal Contraceptive Users $) ; *$ p <.05;** $<$ <.01 
Table 9

Predicting involuntary memory frequency in HC users, LF women, and FF women $(N=$ 76)

\begin{tabular}{lccc}
\hline \multirow{2}{*}{ Predictors } & \multicolumn{3}{c}{ Frequency } \\
\cline { 2 - 4 } & Model 1 & Model 2 & Model 3 \\
\hline 1. Depression & $0.05^{* *}$ & $0.07^{* *}$ & $0.07^{* *}$ \\
2. Brooding Rumination & - & -0.02 & 0.03 \\
3. Luteal & - & 0.06 & 0.07 \\
4. HC & - & -0.15 & -0.15 \\
5. Interaction 2x3 & - & - & -0.06 \\
6. Interaction 2x4 & - & - & -0.07 \\
$R^{2}$ & $0.11^{* *}$ & $0.16^{*}$ & $0.18^{*}$ \\
$\Delta R^{2}$ & - & 0.05 & 0.02 \\
\hline
\end{tabular}

Note. Values reported in this table are unstandardized regression weights $(b)$ unless otherwise labeled; LF=Luteal Phase; FF=Follicular Phase; Luteal $(1=$ Luteal, $0=$ Others $)$;C $=$ Hormonal Contraceptive Users $(1=$ Hormonal Contraceptive Users, $0=$ Others); $* p<.05 ; * p<.01$ 
Table 10

Predicting involuntary memory related distress in HC users, LF women, and FF women $(N=76)$

\begin{tabular}{lccc}
\hline \multicolumn{1}{c}{ Predictors } & \multicolumn{3}{c}{ Distress } \\
\cline { 2 - 4 } & Model 1 & Model 2 & Model 3 \\
\hline 1. Depression & $0.04^{*}$ & $0.05^{*}$ & 0.05 \\
2. Brooding Rumination & - & -0.02 & 0.02 \\
3. Luteal & - & -0.01 & $<-0.01$ \\
4. HC & - & -0.10 & -0.09 \\
5. Interaction 2x3 & - & - & -0.04 \\
6. Interaction 2x4 & - & - & -0.07 \\
$R^{2}$ & $0.06^{*}$ & 0.08 & 0.10 \\
$\Delta R^{2}$ & - & 0.02 & 0.02 \\
\hline
\end{tabular}

Note. Values reported in this table are unstandardized regression weights $(b)$ unless otherwise labeled; LF=Luteal Phase; FF=Follicular Phase; Luteal $(1=$ Luteal, $0=$ Others $)$; HC = Hormonal Contraceptive Users $(1=$ Hormonal Contraceptive Users, $0=$ Others); $* p<.05 ; * * p<.01$ 
Table 11

Predicting involuntary memory related interference in HC users, LF women, and FF women $(N=76)$

\begin{tabular}{lccc}
\hline \multicolumn{1}{c}{ Predictors } & \multicolumn{3}{c}{ Interference } \\
\cline { 2 - 4 } & Model 1 & Model 2 & Model 3 \\
\hline 1. Depression & -0.01 & -0.01 & -0.01 \\
2. Brooding Rumination & - & $<0.01$ & $<-0.01$ \\
3. Luteal & - & 0.02 & 0.03 \\
4. HC & - & $<-0.01$ & $<0.01$ \\
5. Interaction 2x3 & - & - & -0.01 \\
6. Interaction 2x4 & - & - & 0.02 \\
$R^{2}$ & 0.01 & 0.01 & 0.03 \\
$\Delta R^{2}$ & - & 0.00 & 0.02 \\
\hline
\end{tabular}

Note. Values reported in this table are unstandardized regression weights $(b)$ unless otherwise labeled; LF=Luteal Phase; FF=Follicular Phase; Luteal $(1=$ Luteal, $0=$ Others $) ; \mathrm{HC}=$ Hormonal Contraceptive Users $(1=$ Hormonal Contraceptive Users, $0=$ Others); $* p<.05 ; * * p<.01$ 
Table 12

Predicting combined total frequency and intensity of involuntary memories in HC users, $L F$ women, and FF women $(N=76)$

\begin{tabular}{lccc}
\hline \multirow{2}{*}{ Predictors } & \multicolumn{3}{c}{ Combined Total Frequency and Intensity } \\
\cline { 2 - 4 } & Model 1 & Model 2 & Model 3 \\
\hline 1. Depression & $0.08^{*}$ & $0.10^{*}$ & $0.10^{*}$ \\
2. Brooding Rumination & - & -0.04 & 0.07 \\
3. Luteal & - & -0.01 & $<-0.01$ \\
4. HC & - & -0.36 & -0.35 \\
5. Interaction 2x3 & - & - & -0.10 \\
6. Interaction 2x4 & - & - & -0.16 \\
$R^{2}$ & $0.06^{*}$ & 0.10 & 0.12 \\
$\Delta R^{2}$ & - & 0.04 & 0.02 \\
\hline
\end{tabular}

Note. Values reported in this table are unstandardized regression weights $(b)$ unless otherwise labeled; LF=Luteal Phase; FF=Follicular Phase; Luteal $(1=$ Luteal, $0=$ Others $) ; \mathrm{HC}=$ Hormonal Contraceptive Users $(1=$ Hormonal Contraceptive Users, $0=$ Others); $* p<.05 ; * * p<.01$ 
Figure 2

Involuntary memory frequency over one week follow-up

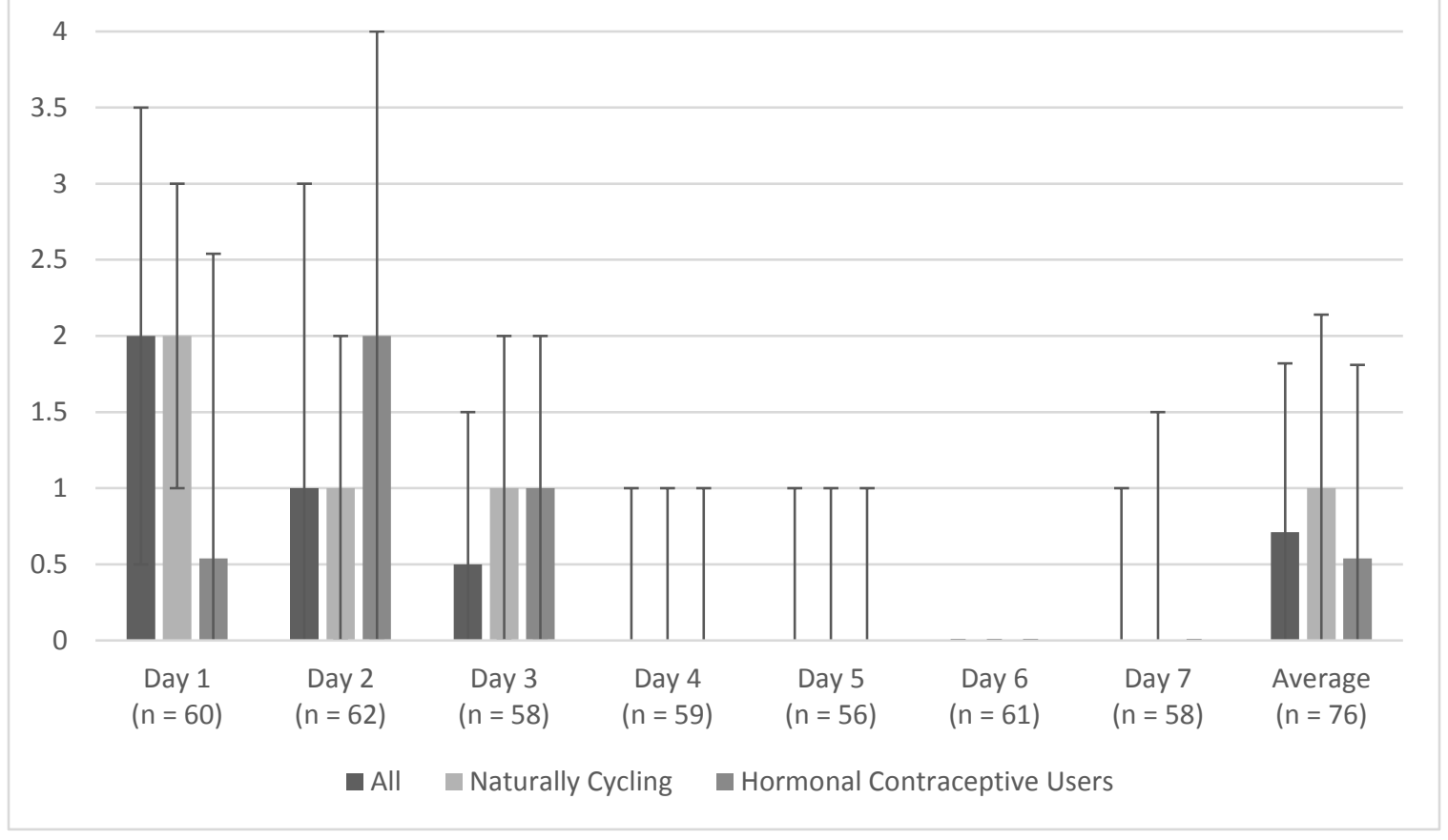

Note. Bars depict median values; Error bars indicate $I Q R$ values 
Figure 3

Intensity of distress experienced as a result of involuntary memories over one week follow-up

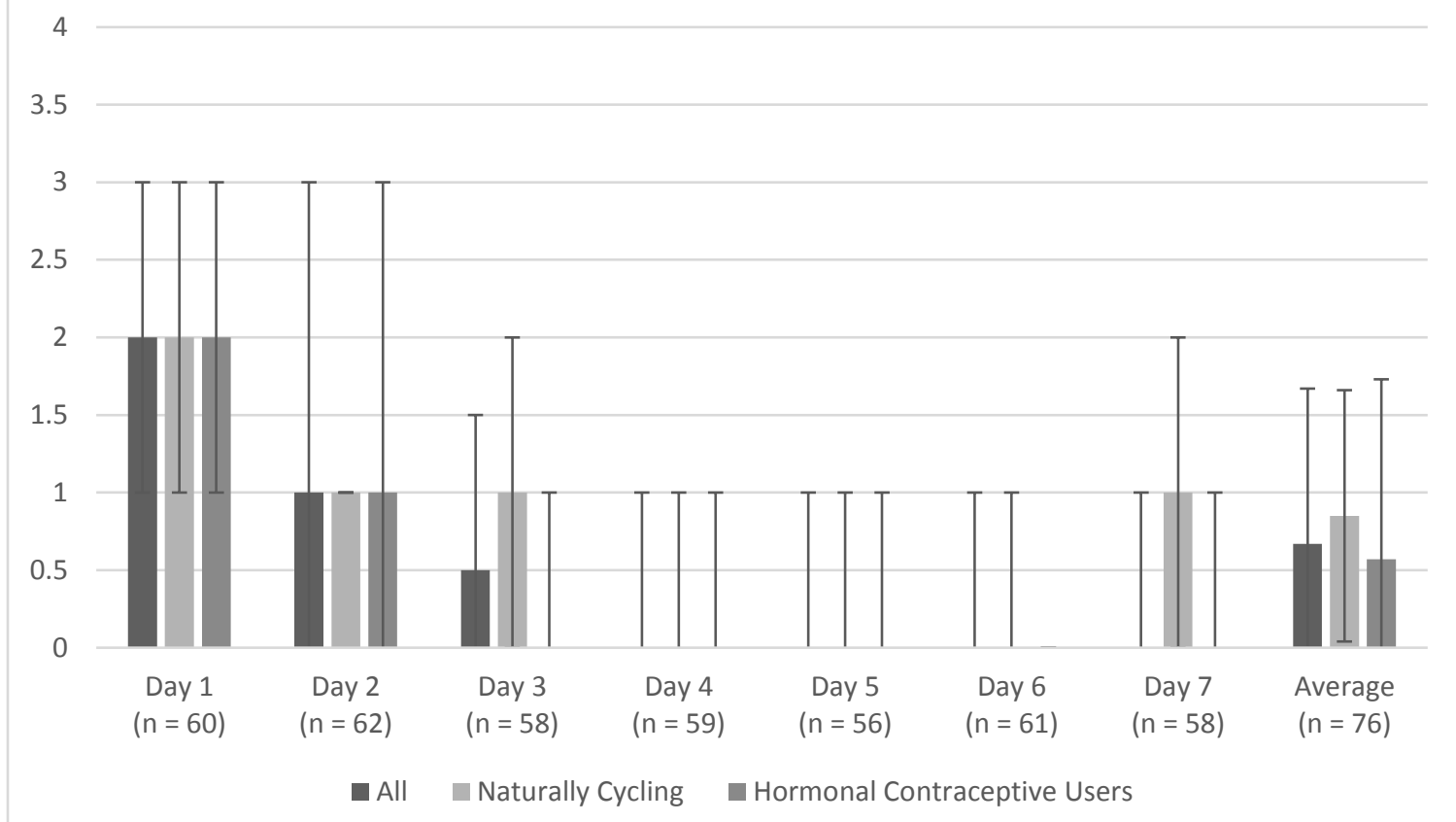

Note. Bars depict median values; Error bars indicate $I Q R$ values 
Figure 4

Intensity of interference caused by involuntary memories over one week follow-up
4

3.5

3

2.5

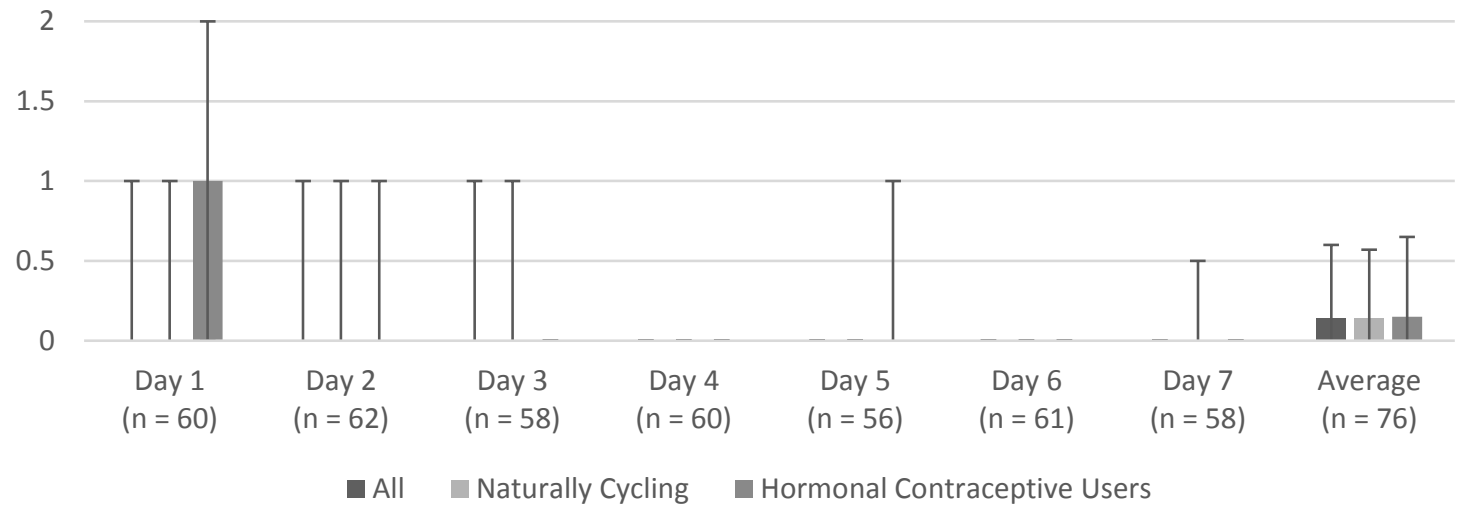

Note. Bars depict median values; Error bars indicate $I Q R$ values 
Figure 5

Combined total frequency and intensity of involuntary memories over one week follow-up

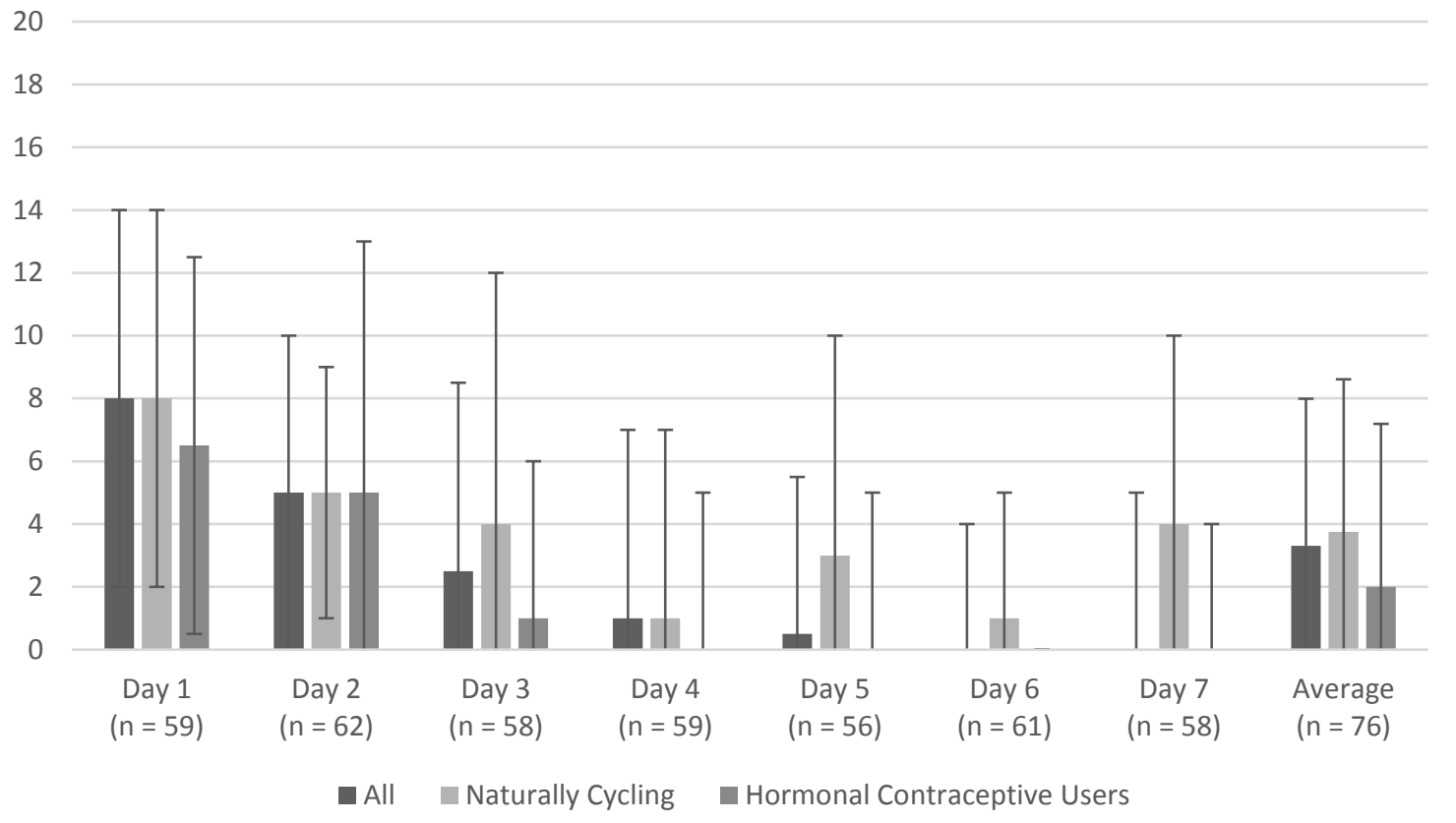

Note. Bars depict median values; Error bars indicate $I Q R$ values 


\section{REFERENCES}

American Psychiatric Association. (2013). Diagnostic and Statistical Manual of Mental Disorders ( $5^{\text {th }}$ ed.) Washington, DC: Author.

American Psychiatric Association. (2013). DSM-5 Self-Rated Level 1 Cross-Cutting Symptom Measure_-Adult. Retrieved from https://www.psychiatry.org/psychiatrists/practice/dsm/educationalresources/assessment-measures

Andreano, J. M., \& Cahill, L. (2010). Menstrual cycle modulation of medial temporal activity evoked by negative emotion. NeuroImage, 53(4), 1286-1293. doi:10.1016/j.neuroimage.2010.07.011

Arnaudova, I., \& Hagenaars, M. A. (2017). Lights ... action: Comparison of trauma films for use in the trauma film paradigm. Behaviour Research and Therapy, 93, 67-77. doi:10.1016/J.BRAT.2017.02.007

Bäckström, T., Haage, D., Löfgren, M., Johansson, I. M., Strömberg, J., Nyberg, S., ... Bengtsson, S. K. (2011). Paradoxical effects of GABA-A modulators may explain sex steroid induced negative mood symptoms in some persons. Neuroscience, 191, 46-54. doi:10.1016/j.neuroscience.2011.03.061

Barth, C., Villringer, A., \& Sacher, J. (2015). Sex hormones affect neurotransmitters and shape the adult female brain during hormonal transition periods. Frontiers in Neuroscience, 9, 37. doi:10.3389/fnins.2015.00037

Bayer, J., Schultz, H., Gamer, M., \& Sommer, T. (2014). Menstrual-cycle dependent 
fluctuations in ovarian hormones affect emotional memory. Neurobiology of Learning and Memory, 110, 55-63. doi:10.1016/j.nlm.2014.01.017

Behar, E., Alcaine, O., Zuellig, A., \& Borkovec, T. D. (2003). Screening for generalized anxiety disorder using the Penn State Worry Questionnaire: a receiver operating characteristic analysis. Journal of Behavior Therapy and Experimental Psychiatry, 34(1), 25-43. doi:10.1016/S0005-7916(03)00004-1

Berman, M. G., Peltier, S., Nee, D. E., Kross, E., Deldin, P. J., \& Jonides, J. (2011). Depression, rumination and the default network. Social Cognitive and Affective Neuroscience, 6(5), 548-555. doi:10.1093/scan/nsq080

Blagden, J. C., \& Craske, M. G. (1996). Effects of active and passive rumination and distraction: A pilot replication with anxious mood. Journal of Anxiety Disorders, 10(4), 243-252. doi:10.1016/0887-6185(96)00009-6

Bradley, M. M., Codispoti, M., Sabatinelli, D., \& Lang, P. J. (2001). Emotion and motivation II: Sex differences in picture processing. Emotion, 1(3), 300-319. doi:10.1037//1528-3542.1.3.300

Breslau, N., \& Anthony, J. C. (2007). Gender differences in the sensitivity to posttraumatic stress disorder: An epidemiological study of urban young adults. Journal of Abnormal Psychology, 116(3), 607-611. doi:10.1037/0021843X.116.3.607

Brinton, Diaz, R., Thompson, R. F., Foy, M. R., Baudry, M., Wang, J., Finch, C. E., ... Nilsen, J. (2008). Progesterone receptors : Form and function in brain. Frontiers in Neuroendocrinology, 29(2), 313-39. doi:10.1016/j.yfrne.2008.02.001

Bryant, R. A., Felmingham, K. L., Silove, D., Creamer, M., O’Donnell, M., \& 
McFarlane, A. C. (2011). The association between menstrual cycle and traumatic memories. Journal of Affective Disorders, 131(1-3), 398-401.

doi:10.1016/j.jad.2010.10.049

Cahill, L., Haier, R. J., Fallon, J., Alkire, M. T., Tang, C., Keator, D., ... McGaugh, J. L. (1996). Amygdala activity at encoding correlated with long-term, free recall of emotional information. Proceedings of the National Academy of Sciences, 93(15), 8016-8021. doi:10.1073/pnas.93.15.8016

Canli, T., Desmond, J. E., Zhao, Z., \& Gabrieli, J. D. E. (2002). Sex differences in the neural basis of emotional memories. Proceedings of the National Academy of Sciences of the United States of America, 99(16), 10789-10794. doi:10.1073/pnas.162356599

Carmassi, C., Stratta, P., Massimetti, G., Bertelloni, C. A., Conversano, C., Cremone, I. M., ... Dell'Osso, L. (2014). New DSM-5 maladaptive symptoms in PTSD: gender differences and correlations with mood spectrum symptoms in a sample of high school students following survival of an earthquake. Annals of General Psychiatry, 13, 28. doi:10.1186/s12991-014-0028-9

Cheung, J., Chervonsky, L., Felmingham, K. L., \& Bryant, R. A. (2013). The role of estrogen in intrusive memories. Neurobiology of Learning and Memory, 106, 87-94. doi:10.1016/j.nlm.2013.07.005

Chou, C.-Y., Marca, R. La, Steptoe, A., \& Brewin, C. R. (2014). Heart rate, startle response, and intrusive trauma memories. Psychophysiology, 51(3), 236-246. doi:10.1111/psyp.12176

Clark I. A., Mackay C. E., \& Holmes E. A. (2015). Low emotional response to traumatic 
footage is associated with an absence of analogue flashbacks: An individual participant data meta-analysis of 16 trauma film paradigm experiments. Cognition and Emotion, 29, 702-713.

Cole, L. A., Ladner, D. G., \& Byrn, F. W. (2009). The normal variabilities of the menstrual cycle. Fertility and Sterility, 91(2), 522-7.

doi:10.1016/j.fertnstert.2007.11.073

D’Arpe, S., Di Feliciantonio, M., Candelieri, M., Franceschetti, S., Piccioni, M. G., \& Bastianelli, C. (2016). Ovarian function during hormonal contraception assessed by endocrine and sonographic markers: a systematic review. Reproductive BioMedicine Online, 33(4), 436-448. doi:10.1016/j.rbmo.2016.07.010

Daniels, K., \& Mosher, W. D. (2013). Contraceptive methods women have ever used: United States, 1982-2010. National Health Statistics Reports, 62, 1-15.

Elliott-Sale, K. J., Smith, S., Bacon, J., Clayton, D., McPhilimey, M., Goutianos, G., ... Sale, C. (2012). Examining the role of oral contraceptive users as an experimental and/or control group in athletic performance studies. Contraception, 88(3), 408-12. doi: 10.1016/j.contraception.2012.11.023

Enders, C. K. (2010). Applied missing data.com: Macro programs. Retrieved from http://www.appliedmissingdata.com/littles-mcar-test.sas

Ertman, N., Andreano, J. M., \& Cahill, L. (2011). Progesterone at encoding predicts subsequent emotional memory. Learning \& Memory, 18(12), 759-763. doi:10.1101//m.023267.111

Ferree, N. K., \& Cahill, L. (2009). Post-event spontaneous intrusive recollections and strength of memory for emotional events in men and women. Consciousness and 
Cognition, 18(1), 126-134. doi:10.1016/j.concog.2008.11.008

Ferree, N. K., Kamat, R., \& Cahill, L. (2011). Influences of menstrual cycle position and sex hormone levels on spontaneous intrusive recollections following emotional stimuli. Consciousness and Cognition, 20(4), 1154-1162.

doi:10.1016/j.concog.2011.02.003

Ferree, N. K., Wheeler, M., \& Cahill, L. (2012). The influence of emergency contraception on post-traumatic stress symptoms following sexual assault. Journal of Forensic Nursing, 8(3), 122-130. doi:10.1111/j.1939-3938.2012.01134.x

Fullerton, C. S., Ursano, R. J., Epstein, R. S., Crowley, B., Vance, K., Kao, T. C., ... Baum, a. (2001). Gender differences in posttraumatic stress disorder after motor vehicle accidents. The American Journal of Psychiatry, 158(9), 1486-1491. doi:10.1176/appi.ajp.158.9.1486

Gillies, G. E., \& McArthur, S. (2010). Estrogen Actions in the Brain and the Basis for Differential Action in Men and Women: A Case for Sex-Specific Medicines. Pharmacological Reviews, 62(2), 155-198. doi:10.1124/pr.109.002071

Goldstein, J. M., Jerram, M., Poldrack, R., Ahern, T., Kennedy, D. N., Seidman, L. J., \& Makris, N. (2005). Hormonal cycle modulates arousal circuitry in women using functional magnetic resonance imaging. Journal of Neuroscience, 25(40), 93099316. doi:10.1523/JNEUROSCI.2239-05.2005

Green, S. B. (1991). How Many Subjects Does It Take To Do A Regression Analysis. Multivariate Behavioral Research, 26(3), 499-510. doi:10.1207/s15327906mbr2603_7

Hagemann, G., Ugur, T., Schleussner, E., Mentzel, H.-J., Fitzek, C., Witte, O. W., \& 
Gaser, C. (2011). Changes in brain size during the menstrual cycle. PloS One. doi:10.1371/journal.pone.0014655

Hamstra, D. A., de Kloet, E. R., Tollenaar, M., Verkuil, B., Manai, M., Putman, P., \& Van der Does, W. (2016). Mineralocorticoid receptor haplotype moderates the effects of oral contraceptives and menstrual cycle on emotional information processing. Journal of Psychopharmacology, 30(10), 1054-1061. doi: $10.1177 / 0269881116647504$

Hawkins, K. A., \& Cougle, J. R. (2013). The effects of nicotine on intrusive memories in nonsmokers. Experimental and Clinical Psychopharmacology, 21(6), 434-442. doi:10.1037/a0033966

Holmes, E. A., \& Bourne, C. (2008). Inducing and modulating intrusive emotional memories: A review of the trauma film paradigm. Acta Psychologica, 127(3), 55366. doi:10.1016/j.actpsy.2007.11.002

Holmes, E. A., Brewin, C. R., \& Hennessy, R. G. (2004). Trauma Films, Information Processing, and Intrusive Memory Development. Journal of Experimental Psychology: General, 133(1), 3-22. doi:10.1037/0096-3445.133.1.3

Hourani, L., Williams, J., Bray, R., \& Kandel, D. (2015). Gender differences in the expression of PTSD symptoms among active duty military personnel. Journal of Anxiety Disorders, 29, 101-8. doi:10.1016/j.janxdis.2014.11.007

James, E. L., Lau-Zhu, A., Clark, I. A., Visser, R. M., Hagenaars, M. A., \& Holmes, E. A. (2016). The trauma film paradigm as an experimental psychopathology model of psychological trauma: intrusive memories and beyond. Clinical Psychology Review, 47, 106-142. doi:10.1016/j.cpr.2016.04.010 
Johnson, D. P., \& Whisman, M. A. (2013a). Gender differences in rumination: A metaanalysis. Personality and Individual Differences, 55(4), 367-374.

doi:10.1016/J.PAID.2013.03.019

Kessler, R. C., Berglund, P., Demler, O., Jin, R., Merikangas, K. R., \& Walters, E. E. (2005). Lifetime prevalence and age-of-onset distributions of DSM-IV disorders in the National Comorbidity Survey Replication. Archives of General Psychiatry, 62(6), 593-602.

Kilpatrick, D. G., Resnick, H. S., Milanak, M. E., Miller, M. W., Keyes, K. M., \& Friedman, M. J. (2013). National Estimates of Exposure to Traumatic Events and PTSD Prevalence Using DSM-IV and DSM-5 Criteria. Journal of Traumatic Stress, 26(5), 537-547. doi:10.1002/jts.21848

Kubota, R., Nixon, R. D. V, \& Chen, J. (2014). Trauma-related rumination mediates the effect of naturally occurring depressive symptoms but not momentary low mood on trauma intrusions. Australian Journal of Psychology, 67(2), 75-86.

doi:10.1111/ajpy.12074

Kuehner, C., \& Weber, I. (1999). Responses to depression in unipolar depressed patients: an investigation of Nolen-Hoeksema's response styles theory. Psychological Medicine, 29(6), 1323-1333. doi:10.1017/S0033291799001282

Mandell, D., Siegle, G. J., Shutt, L., Feldmiller, J., \& Thase, M. E. (2014). Neural substrates of trait ruminations in depression. Journal of Abnormal Psychology, 123(1), 35-48. doi:10.1037/a0035834

Manea, L., Gilbody, S., \& McMillan, D. (2012). Optimal cut-off score for diagnosing depression with the Patient Health Questionnaire (PHQ-9): a meta-analysis. CMAJ : 
Canadian Medical Association Journal = Journal de l'Association Medicale

Canadienne, 184(3), E191-6. doi:10.1503/cmaj.110829

Marečková, K., Perrin, J. S., Khan, I. N., Lawrence, C., Dickie, E., McQuiggan, D. A., \& Paus, T. (2014). Hormonal contraceptives, menstrual cycle and brain response to faces. Social Cognitive and Affective Neuroscience, 9(2), 191-200.

doi:10.1093/scan/nss 128

Marks, E. H., Franklin, A. R., \& Zoellner, L. A. (2018). Can't get it out of my mind: A systematic review of predictors of intrusive memories of distressing events.

Psychological Bulletin, 144(6), 584-640. doi:10.1037/bul0000132

McGaugh, J. L., Cahill, L., \& Roozendaal, B. (1996). Involvement of the amygdala in memory storage: interaction with other brain systems. Proceedings of the National Academy of Sciences of the United States of America, 93(24), 13508-13514.

doi:10.1073/pnas.93.24.13508

McLaughlin, K. A., Borkovec, T. D., \& Sibrava, N. J. (2007). The Effects of Worry and Rumination on Affect States and Cognitive Activity. Behavior Therapy, 38(1), 2338. doi:10.1016/j.beth.2006.03.003

Milner, J. S., Wagner, M. F., \& Crouch, J. L. (2017). Reducing Child-Related Negative Attitudes, Attributions of Hostile Intent, Anger, Harsh Parenting Behaviors, and Punishment Through Evaluative Conditioning. Cognitive Therapy and Research, 41(1), 43-61. doi:10.1007/s10608-016-9800-2

Montoya, E. R., \& Bos, P. A. (2017). How Oral Contraceptives Impact Social-Emotional Behavior and Brain Function. Trends in Cognitive Sciences, 21(2), 125-136. doi:10.1016/j.tics.2016.11.005 
Murty, V. P., Ritchey, M., Adcock, R. A., \& LaBar, K. S. (2010). FMRI studies of successful emotional memory encoding: A quantitative meta-analysis. Neuropsychologia, 48(12), 1459-69. doi:10.1016/j.neuropsychologia.2010.07.030

Nielsen, S. E., Ertman, N., Lakhani, Y. S., \& Cahill, L. (2011). Hormonal contraception usage is associated with altered memory for an emotional story. Neurobiology of Learning and Memory, 96(2), 378-84. doi:10.1016/j.nlm.2011.06.013

Nielsen, S. E., Segal, S. K., Worden, I. V, Yim, I. S., \& Cahill, L. (2013). Hormonal contraception use alters stress responses and emotional memory. Biological Psychology, 92(2), 257-266. doi:10.1016/j.biopsycho.2012.10.007

Nolen-Hoeksema, S. (2012). Emotion Regulation and Psychopathology: The Role of Gender. Annual Review of Clinical Psychology, 8, 161-187. doi:10.1146/annurevclinpsy-032511-143109

Nolen-Hoeksema, S., Morrow, J., \& Fredrickson, B. L. (1993). Response styles and the duration of episodes of depressed mood. Journal of Abnormal Psychology, 102(1), 20-28. doi:10.1037/0021-843X.102.1.20

Orsillo, S. M., Raja, S., \& Hammond, C. (2002). Gender issues in PTSD with comorbid mental health disorders. In R. Kimerling, P. Ouimette, \& J. Wolfe (Eds.), Gender and PTSD (pp. 207-231). New York, NY, US: The Guilford Press.

Petersen, N., \& Cahill, L. (2014). Amygdala reactivity to negative stimuli is influenced by oral contraceptive use. Social Cognitive and Affective Neuroscience, 10(9), 12661272. doi:10.1093/scan/nsv010

Petersen, N., Kilpatrick, L. A., Goharzad, A., \& Cahill, L. (2014). Oral contraceptive pill use and menstrual cycle phase are associated with altered resting state functional 
connectivity. NeuroImage, 90, 24-32. doi:10.1016/j.neuroimage.2013.12.016

Pletzer, B. A., \& Kerschbaum, H. H. (2014). 50 years of hormonal contraception - time to find out, what it does to our brain. Frontiers in Neuroscience, 8, 256. doi:10.3389/fnins.2014.00256

Pletzer, B., Kronbichler, M., Aichhorn, M., Bergmann, J., Ladurner, G., \& Kerschbaum, H. H. (2010). Menstrual cycle and hormonal contraceptive use modulate human brain structure. Brain Research, 1348, 55-62. doi: 10.1016/j.brainres.2010.06.019

Protopopescu, X., Butler, T., Pan, H., Root, J., Altemus, M., Polanecsky, M., ... Stern, E. (2008). Hippocampal structural changes across the menstrual cycle. Hippocampus, 18(10), 985-8. doi:10.1002/hipo.20468

Protopopescu, X., Pan, H., Altemus, M., Tuescher, O., Polanecsky, M., McEwen, B., ... Stern, E. (2005). Orbitofrontal cortex activity related to emotional processing changes across the menstrual cycle. Proceedings of the National Academy of Sciences of the United States of America, 102(44), 16060-16065. doi:10.1073/pnas.0502818102

Ray, R. D., Ochsner, K. N., Cooper, J. C., Robertson, E. R., Gabrieli, J. D. E., \& Gross, J. J. (2005). Individual differences in trait rumination and the neural systems supporting cognitive reappraisal. Cognitive, Affective \& Behavioral Neuroscience, 5(2), 156-168. doi:10.3758/CABN.5.2.156

Rood, L., Roelofs, J., Bögels, S. M., Nolen-Hoeksema, S., \& Schouten, E. (2009). The influence of emotion-focused rumination and distraction on depressive symptoms in non-clinical youth: A meta-analytic review. Clinical Psychology Review, 29(7), 60716. doi:10.1016/j.cpr.2009.07.001 
Rubin, D. C., Berntsen, D., \& Bohni, M. K. (2008). A memory-based model of posttraumatic stress disorder: Evaluating basic assumptions underlying the PTSD diagnosis. Psychological Review, 115(4), 985-1011. doi:10.1037/a0013397

Rubin, D. C., Boals, A., \& Berntsen, D. (2008). Memory in posttraumatic stress disorder: Properties of voluntary and involuntary, traumatic and nontraumatic autobiographical memories in people with and without posttraumatic stress disorder symptoms. Journal of Experimental Psychology: General, 137(4), 591-614. doi:10.1037/a0013165

Rubin, D. C., Schulkind, M. D., \& Rahhal, T. a. (1999). A study of gender differences in autobiographical memory: Broken down by age and sex. Journal of Adult Development, 6(1), 61-71. doi:10.1023/a:1021676309064

Salters-Pedneault, K., Vine, V., Mills, M. A., Park, C., \& Litz, B. T. (2009). The Experience of Intrusions Scale: a preliminary examination. Anxiety, Stress, and Coping, 22(1), 27-37. doi:10.1080/10615800802403823

Satyshur, M. D., Layden, E. A., Gowins, J. R., Buchanan, A., \& Gollan, J. K. (2018). Functional connectivity of reflective and brooding rumination in depressed and healthy women. Cognitive, Affective, \& Behavioral Neuroscience, 18(5), 884-901. doi:10.3758/s13415-018-0611-7

Siegle, G. J., Moore, P. M., \& Thase, M. E. (2004). Rumination: One construct, many features in healthy individuals, depressed individuals, and individuals with lupus. Cognitive Therapy and Research. doi:10.1023/B:COTR.0000045570.62733.9f

Smets, J., Luyckx, K., Wessel, I., \& Raes, F. (2012). Depressed mood mediates the relationship between rumination and intrusions. Australian Journal of Psychology, 
64(4), 209-216. doi:10.1111/j.1742-9536.2012.00056.x

Soni, M., Curran, V. H., \& Kamboj, S. K. (2013). Identification of a narrow postovulatory window of vulnerability to distressing involuntary memories in healthy women. Neurobiology of Learning and Memory, 104, 32-38.

doi:10.1016/j.nlm.2013.04.003

Spalek, K., Loos, E., Schicktanz, N., Hartmann, F., de Quervain, D., Stier, C., \& Milnik, A. (2019). Women using hormonal contraceptives show increased valence ratings and memory performance for emotional information. Neuropsychopharmacology, 44(7), 1258-1264. doi:10.1038/s41386-019-0362-3

Steel, Z., Marnane, C., Iranpour, C., Chey, T., Jackson, J. W., Patel, V., \& Silove, D. (2014). The global prevalence of common mental disorders: a systematic review and meta-analysis 1980-2013. International Journal of Epidemiology, 43(2), 476-93. doi:10.1093/ije/dyu038

Stein, M. B., Walker, J. R., \& Forde, D. R. (2000). Gender differences in susceptibility to posttraumatic stress disorder. Behaviour Research and Therapy, 38(6), 619-28.

Szabo, Y. Z., Warnecke, A. J., Newton, T. L., \& Valentine, J. C. (2017). Rumination and posttraumatic stress symptoms in trauma-exposed adults: a systematic review and meta-analysis. Anxiety, Stress \& Coping, 30(4), 396-414.

doi:10.1080/10615806.2017.1313835

Tabachnick, B. G., \& Fidell, L. S. (2013). Using multivariate statistics (6th ed.). New York: Harper and Row. doi:10.1037/022267

Tamres, L. K., Janicki, D., \& Helgeson, V. S. (2002). Sex Differences in Coping Behavior: A Meta-Analytic Review and an Examination of Relative Coping. 
Personality and Social Psychology Review, 6(1), 2-30.

doi:10.1207/S15327957PSPR0601_1

Tolin, D. F., \& Foa, E. B. (2006). Sex differences in trauma and posttraumatic stress disorder: A quantitative review of 25 years of research. Psychological Bulletin, 132(6), 959-992. doi:10.1037/0033-2909.132.6.959

Treynor, W., Gonzalez, R., \& Nolen-Hoeksema, S. (2003). Rumination reconsidered: A psychometric analysis. Cognitive Therapy and Research, 27(3), 247-259. doi:10.1023/A:1023910315561

Wang, X., Chen, Z., Poon, K.-T., Teng, F., \& Jin, S. (2017). Self-compassion decreases acceptance of own immoral behaviors. Personality and Individual Differences, 106, 329-333. doi:10.1016/J.PAID.2016.10.030

Watkins, E. (2004). Adaptive and maladaptive ruminative self-focus during emotional processing. Behaviour Research and Therapy, 42(9), 1037-1052. doi:10.1016/j.brat.2004.01.009

Watson, D., Clark, L. A., \& Tellegen, A. (1988). Development and validation of brief measures of positive and negative affect: The PANAS scales. Journal of Personality and Social Psychology, 54(6), 1063-1070. doi:10.1037/0022-3514.54.6.1063

Wegerer, M., Kerschbaum, H., Blechert, J., \& Wilhelm, F. H. (2014). Low levels of estradiol are associated with elevated conditioned responding during fear extinction and with intrusive memories in daily life. Neurobiology of Learning and Memory, 116, 145-54. doi:10.1016/j.nlm.2014.10.001

Wolfe, J., \& Kimerling, R. (1997). Gender issues in the assessment of posttraumatic stress disorder. In J.P. Wilson \& T.M. Keane (Eds.), Assessing psychological trauma 
and PTSD (pp. 192 238). New York, NY, US: The Guilford Press.

Wolpe, J. (1969). The practice of behavior therapy (2nd ed.). New York: Pergamon Press. 


\section{CURRICULUM VITAE}

Samantha C. Patton, MS

\begin{tabular}{ll}
\hline EDUCATION & \\
\hline $\mathbf{2 0 1 6 - 2 0 1 9}$ & University of Louisville, Louisville, KY \\
& Doctor of Philosophy in Clinical Psychology \\
$\mathbf{2 0 1 8 - 2 0 1 9}$ & Southeast Louisiana Veterans Health Care System (SLVHCS), New Orleans, \\
& LA \\
& Internship \\
$\mathbf{2 0 1 4 - 2 0 1 6}$ & University of Louisville, Louisville, KY \\
& Master of Science \\
$\mathbf{2 0 0 6 - 2 0 1 0}$ & University of Memphis, Memphis, TN \\
& Bachelor of Arts in Psychology with a minor in German and a concentration in \\
& Behavioral Neuroscience, cum laude \\
RESEARCH EXPERIENCE
\end{tabular}

2018-2019

PSYCHOLOGY INTERN, DAT Lab, Southeast Louisiana Veterans Healthcare

System, New Orleans, LA

Supervisors: Laurel Franklin, PhD \& Amanda Raines, PhD

- Major Projects:

- Complete manuscript examining relationship between demographics and PTSD symptoms 
DOCTORAL STUDENT, Stress and Health Lab, University of Louisville, Department of Psychological and Brain Sciences

Supervisor: Tamara Newton, $\mathrm{PhD}$

- Major Projects:

- Complete dissertation examining hormonal status, emotion regulation, and involuntary memory in women following trauma analogue exposure

- Complete a systematic review of the literature examining the health impact of IPV in longitudinal studies examining women who have left their abusers

- Assisting with a functional magnetic resonance imaging study that aims to examine an emotion regulation training paradigm

- Responsibilities: run participants through lab protocols, collect and store saliva samples, analyze saliva samples for both cytokine and protein concentrations, assist in manuscript preparation, conduct data analysis in FreeSurfer and FSL, conduct data analysis using SAS, mentor undergraduate students

2012-2014

PSYCHOLOGY RESEARCH TECHNICIAN, National Center for Posttraumatic Stress Disorder, Women's Health Sciences Division, VA Boston Healthcare System, Boston, MA

Supervisors: Suzanne Pineles, PhD and Ann Rasmusson, MD

- Major Projects:

- Managed a VA funded investigation of psychophysiological and neurobiological changes in women with Posttraumatic Stress Disorder (PTSD) at distinctly different phases of the menstrual cycle

- Managed a study funded by the Center of Integration of Medicine and Innovative Technologies assessing event-related P2 slope as a predictor of responsiveness to selective serotonin-reuptake inhibitors in Veterans with PTSD

- Managed a federally funded pilot study investigating the ability to improve efficacy of treatment based on natural hormone fluctuation in women with specific phobia

$\circ$ Assisted with a federally funded investigation of psychophysiological, neurobiological, and psychological predictors of smoking cessation success in individuals with PTSD

- Responsibilities: recruited, screened participants, consented participants, ran participants through a range of psychophysiological (e.g. fear conditioning, startle, pre-pulse inhibition, and electroencephalogram) and neurobiological (centrifuge and aliquot blood plasma and serum, store and ship samples) procedures, prepared and maintained study materials, managed budget and IRB paperwork, trained new staff on psychophysiological procedures, created and managed study databases, assisted in grant preparation, conducted data analysis, assisted with scoring measures by creating syntax, authored manuscripts and poster presentations, actively participated in laboratory and division meetings

2011-2012

RESEARCH TECHNICIAN, University of Tennessee Health Science Center, Department of Preventative Medicine Supervisors: Susan Thomas, RN 
2010-2012

2009-2010

2008-2010

- Major Projects: Assisted with a large longitudinal investigation of conditions affecting neurocognitive development in the first years of life

- Responsibilities: interviewed mothers about many aspects of their child's daily life and dietary habits as well as their own, collected buccal swabs, collected hair samples, conducted home visits to gather information on home environment, managed the clinic, ordered supplies for the clinic, acted as a liaison between the study staff and the cognitive examiners, scheduled annual clinic visits, administered brief physical exams, assessed participants for depression and suicidality, recruited for sub studies, trained new staff, actively participated in business meetings

PSYCHOLOGY RESEARCH ASSISTANT, University of Memphis, Department of Psychology

Supervisors: J. Gayle Beck, PhD

- Major Projects:

- Assisted with a large project examining several different aspects of Interpersonal Violence (IPV)

- Assisted with an NIMH funded investigation into the effects of either deliberately expressing or inhibiting emotion after being exposed to an analogue trauma stimulus

- Responsibilities: consented participants, debriefed participants, entered data, cleaned data, collected psychophysiological data during both traumatic and emotion provoking film clips, coded facial expression data using FACES based methods, actively participated in lab meetings and CAPS consensus meetings, assisted with manuscript preparation

PSYCHOLOGY RESEARCH ASSISTANT, University of Memphis, Department of Psychology Supervisors: Max Louwerse, $\mathrm{PhD}$

- Major Projects:

- Completed an original investigation into the processing of abstract words using a Stroop paradigm

- Responsibilities: used E-Prime to create an original protocol, managed participants and payment, recruitment, assisted in manuscript preparation, entered data, cleaned data, consented and debriefed participants

PSYCHOLOGY RESEARCH ASSISTANT, University of Memphis, Department of Psychology Supervisors: Charles Blaha, $\mathrm{PhD}$

- Major Projects:

- Senior Honors Thesis- "Monitoring Dopamine Concentrations in a Levadopa-Treated Parkinsonian Animal Model Using Fixed Potential Amperometry: A Potential Tool to Enhance the Efficacy of Deep Brain Stimulation Systems to Treat Neurological Disorders"

- Responsibilities: performed stereotaxic surgery on both lesioned and nonlesioned C57BL/6J mice, measured dopamine release using fixed potential amperometry, extracted and cleaned dopamine release data, anesthetized mice, assisted graduate students in making carbon fiber recording electrodes, wrote/proposed/successfully defended an honors thesis 


\section{PUBLISHED MANUSCRIPTS}

Japuntich, S.J., Lee, L.O., Pineles,S.L., Gregor, K., Joos, C., Patton, S.C., Krishnan-Sarin, S., Rasmusson, A.M. (2018). Contingency management and cognitive behavioral therapy for trauma-exposed smokers with and without posttraumatic stress disorder. Addictive Behaviors 90, 136-142. doi: 10.1016/j.addbeh.2018.10.042

Fogleman, N.D., Naaz, F., Knight, L.K., Stoica, T., Patton, S.C., Olson-Madden, J.H., Barnhart, M.C., Hostetter, T.A., Forster, J., Brenner, L.A., Banich, M.T. \& Depue, B.D. (2017). Reduced lateral prefrontal cortical volume is associated with performance on the modified Iowa Gambling Task: A surface based morphometric analysis of previously deployed veterans. Psychiatry Research: Neuroimaging.

Pineles, S. L., Nillni, Y. I., King, M. W., Patton, S. C., Bauer, M. R., Mostoufi, S. M., Gerber, M. R., Hauger, R., Resick, P. A., Rasmusson, A. M., \& Orr, S. P. (2016). Extinction retention and the menstrual cycle: Different associations for women with posttraumatic stress disorder. Journal of Abnormal Psychology. doi: 10.1037/abn0000138

Clapp, J. D., Patton, S. C., \& Beck, J. G. (2015). Expressive inhibition in response to stress: Implications for emotional processing following trauma. Journal of Anxiety Disorders 29, 109-118. doi:10.1016/j.janxdis.2014.11.008

Nillni, Y. I., Pineles, S. L., Patton, S. C., Rouse, M. H., Sawyer, A. T., \& Rasmusson, A. M. (2015). Menstrual cycle effects on psychological symptoms in women with PTSD. Journal of Traumatic Stress, 28(1), 1-7. doi: 10.1002/jts.21984

Beck, J. G., Reich, C. M., Woodward, M. J., Olsen, S. A., McNiff, J., \& Patton, S. C. (2015). How do negative emotions relate to dysfunctional posttrauma cognitions? An examination of interpersonal trauma survivors. Psychological Trauma: Theory, Research, Practice, and Policy, 7(1), 3-10. doi:10.1037/a0032716

Woodward, M. J., Patton, S. C., Olsen, S. A., McNiff, J., Reich, C. M., Blackwell, N., \& Beck, J. G. (2013). How do attachment style and social support contribute to psychopathology following interpersonal trauma? Examining clinician ratings versus self-report. Journal of Anxiety Disorders, 27(3), 312-320. doi: 10.1016/j.janxdis.2013.02.007

UNDER REVIEW MANUSCRIPTS

Patton, S.C., Szabo, Y.Z., \& Newton, T.L. (submitted to Clinical Psychology Review) Health changes after an abusive relationship: A systematic review of longitudinal studies

\section{MANUSCRIPTS IN PREPARATION}

Patton, S.C., Raines, A.M., Cuccurullo, L.J., Walton, J.L., \& Franklin, C.L. Reckless and selfdestructive behaviors: What's age got to do with it?

\section{CONFERENCE PRESENTATIONS}

Patton, S.C., Kane, J., Szabo, Y.Z., Fernandez-Botran, G.R., \& Newton, T. L. (2018, March). Divorce and biological risk for poor health: A role for partner violence? Poster presented at the meeting of the American Psychosomatic Society, Louisville, KY.

Patton, S.C. \& Newton, T.L. (2017, November). Recruiting community women with histories of coercive controlling violence. Poster presented at the meeting of the International Society for Traumatic Stress Studies, Chicago, IL.

Naaz, F., Knight, L.K., Siers, B., Patton, S.C. \& Depue, B.E. (2017, June). Neural changes related to the training of emotion regulation. Poster to be presented at the meeting of the Organization for Human Brain Mapping. Vancouver, BC, Canada. 
Patton, S.C., Szabo, Y.Z., Newton, T.L. (2016, November). Mental and physical health trajectories after leaving an abusive partner: A systematic review. Poster presented at the meeting of the International Society for Traumatic Stress Studies, Dallas, TX.

Fogleman, N.D., Stoica, T., Knight, L.K., Patton, S.C., Naaz, F., Depue, B.E. (2015, October). Decreased volume of the left DLPFC predicts performance on the Modified Iowa Gambling task in PTSD Combat Veterans. Poster presented at Society for Neuroscience, Chicago, IL.

Knight, L.K., Stoica, T., Fogleman, N.D., Patton, S.C., Naaz, F., Depue, B.E. (2015, October). Comprised frontoparietal network in PTSD veterans related to poorer performance during risky decision making. Poster presented at Research!Louisville, Louisville, KY.

Fogleman, N.D., Patton, S.C., Stoica, T., Knight, L.K., Naaz, F., Depue, B.E. (2015, October). Surfacebased morphometry in lateral prefrontal cortex and lateral inferior parietal cortex is associated with impulse inhibition and attention in combat deployed veterans with mild traumatic brain injury. Poster presented at Research!Louisville, Louisville, KY.

Japuntich, S.J., Pineles, S.L., Gregor, K., Krishnan-Sarin, Suchitra, Joos, C., Patton, S.C., Rasmusson, A. (2014, November). Contingency management tobacco treatment for trauma exposed smokers with and without PTSD: A pilot study. Poster presented at the meeting of the International Society for Traumatic Stress Studies, Miami, FL.

Pineles, S. L., Nillni, Y.I., Patton, S.C., Resick, P.A., \& Rasmusson, A.M., \& Orr, S.P. (2013, November). Menstrual Cycle Effects on Conditioned Fear Acquisition in Women with and without PTSD. In How sex and sex-related hormones may affect psychophysiological and psychological correlates of PTSD. Symposium conducted at the meeting of International Society for Traumatic Stress Studies, Philadelphia, PA.

Nillni, Y. I., Pineles, S. L., Patton, S. C., Rouse, M. H., Sawyer, A. T., \& Rasmusson, A. M. (November 2013). The expression of psychological symptoms across the menstrual cycle in women with PTSD. In S. L. Pineles (Chair), How sex and sex-related hormones may affect psychophysiological and psychological correlates of PTSD. Symposium presented at the meeting of the International Society for Traumatic Stress Studies, Philadelphia, PA.

Patton, S.C., Dodson, T.S., Nillni, Y.I., \& Pineles, S.L. (2013, November). Examining physiological non-response by way of avoidance and peritraumatic dissociation in a trauma exposed sample. Poster presented at the meeting of the International Society for Traumatic Stress Studies, Philadelphia, PA.

Patton, S. C., Nillni, Y. I., Pineles, S. L., Rouse, M. H., Sawyer, A. T., \& Rasmusson, A. M. (2013, November). Evidence Suggesting a Fluctuation in Psychological Symptoms Across the Menstrual Cycle in Women with PTSD. Poster presented at the meeting of the Association for Behavioral and Cognitive Therapies, Nashville, TN.

Pineles, S. L., Nillni, Y.I., Patton, S.C., Resick, P.A., Orr, S.P., \& Rasmusson, A.M. (2013, June). Impact of menstrual cycle phase on fear conditioning in women with and without PTSD. In Menstrual Cycle and Psychopathology. Symposium conducted at the meeting of the Society for Menstrual Cycle Research, New York, NY.

Woodward, M. J., Olsen, S. A., McNiff, J., Patton, S., \& Beck, \& J. G. (2012, November). How Do Attachment and Social Support Contribute to Psychopathology? Associations in an Intimate Partner Violence Sample. Poster presented at the meeting of the Association for Behavioral and Cognitive Therapies, National Harbor, MD.

Patton, S., McNiff, J., Jacobs-Lentz, J., Avery, M., Olsen, S. A., Woodward, M., Clapp, J. D., \& Beck, J. G. (2011, November). Attachment as a Predictor of Shame, Guilt, and Distress in Intimate Partner Violence Survivors. Poster presented at the meeting of the Association for Behavioral and Cognitive Therapies, Toronto, ON.

Clapp, J. D., Patton, S., Jacobs-Lentz, J., McNiff, J., Olsen, S. A., Avery, M. L., \& Beck, J.G. (2011, November). Hiding Emotional Reactions Following Domestic Violence: What is 
Unique to PTSD? Poster presented at the meeting of the Association for Behavioral and Cognitive Therapies, Toronto, ON.

Patton, S., Pate, T. P., \& Blaha, C. D. (2010, April). Evidence Showing the Ability of Fixed Potential Amperometry to Increase the Productivity of the Wireless Instantaneous Neurotransmitter Concentration System Using a Levadopa-Treated Parkinsonian Animal Model. Paper presented at the National Conference of Undergraduate Research, Missoula, MT.

Patton, S. \& McElroy, H. (2009, November). Thinking In Color. Paper presented at the Works in Progress Symposium, Memphis, TN.

Patton, S. (2008, November). GPA and Religiosity. Poster presented at the Midsouth Psychology Conference, Jackson, TN.

\section{CLINICAL EXPERIENCE}

2019

2018-2019

2018

2017-2018

2016-2017

2016-2017

2014-2016
COMMUNITY-BASED OUTPATIENT CLINIC and BEHAVIORAL

MEDICINE, Southeast Louisiana Veteran's Healthcare System, New Orleans, LA

- ACT for Chronic Pain (individual and group format), CBT for Chronic Pain, mental health screening in the ALS clinic

PTSD AND SUBSTANCE USE, Southeast Louisiana Veteran's Healthcare System, New Orleans, LA

- Cognitive Processing Therapy, Cognitive Behavioral Therapy for Insomnia and Comorbid PTSD, Motivational Enhancement Therapy, Anger Management

OEF/OIF/OND: TRAUMA, Southeast Louisiana Veteran's Healthcare System, New Orleans, LA

- Prolonged Exposure Therapy, Cognitive Behavioral Therapy for Insomnia, CAPS-5, sole facilitator of the Stress Management and Trauma101 groups, worked with both combat and MST traumas

MINDFULNESS, HEALTH PSYCHOLOGY, AND STRESS REDUCTION TEAM, University of Louisville, Louisville, KY

- This team utilizes third-wave treatments in working with a diverse set of clientele.

U OF L OUTPATIENT PSYCHIATRY PRACTICUM, University of Louisville, Louisville, KY

- Co-lead a Dialectical Behavior Therapy Skills group for adults, gained exposure to the Collaborative Assessment and Management of Suicidality treatment approach, met with and provided therapy to a diverse set of clients with a wide range of concerns in a hospital setting, collaborated with medication providers

INTEGRATIVE PSYCHOTHERAPY TEAM, University of Louisville, Louisville, KY

- The integrative psychotherapy team incorporates a range of empirically based psychological techniques to address presenting clinical concerns.

CARDS TEAM, University of Louisville, Louisville, KY 
- The CARDs treatment team specializes in treating children with ADHD, emotion dysregulation, and related issues.

- Responsibilities: Completed full diagnostic testing on children, ran the Managing Frustration for Children's Group, ran the Managing Frustration for Children's Parent group, provided therapy to children and families

TEACHER COUNSELOR, Youth Villages' Girls' Center for Intensive Residential Treatment, Memphis, TN

- Responsibilities: Maintained the safety of clients through de-escalation and nonviolent crisis intervention if necessary, prepared life lessons and therapeutic activities so that the children could develop more positive behaviors and coping skills, transported clients to and from the residential courtyard to doctor's appointments, good behavior outings, court appointments, etc., shared observations with the counselors assigned to the clients, maintained detailed milieu notes

\section{VOLUNTEER EXPERIENCE \\ 2018 VOLUNTEER, Stand Down Event, Southeast Louisiana Veteran's Healthcare System \\ - Assisted homeless veterans in navigating the event}

2016

2013-2014

2010
VOLUNTEER, Center for Women and Families, Louisville, KY

- Assisted in Shop and Share efforts targeted at obtaining supplies for the shelter, ran the front desk during holiday hours

PLAYSPACE VOLUNTEER, Horizons/REACH, Boston area, MA

- Prepared and lead age appropriate activities, games, and/or projects with children in domestic violence shelters in the Boston area, fostered healthy interactions and play with children, maintained communications with the Playspace program staff

VOLUNTEER, YWCA of Greater Memphis, Memphis, TN

- Cold called domestic violence victims based on police records reaching out and letting them know information about upcoming court dates, observed group therapy sessions, took notes on group therapy sessions for the social worker leading therapy, helped women with their shelter chores, assisted staff in preparing for incoming shelter clients, and educated the community on the prevalence of domestic violence and the resources available at events such as community health fairs

\section{PROFESSIONAL DEVELOPMENT AND SERVICE 2018 TEACHING ASSISTANT, Experimental Psychology, University of Louisville \\ 2017 TEACHING ASSISTANT, Quantitative Methods in Psychology, University of Louisville \\ 2015-2017 \\ TEACHING ASSISTANT, Abnormal Psychology, \\ University of Louisville \\ 2015 \\ TEACHING ASSISTANT, Personality, \\ University of Louisville}


Summer 2015

2014-2016

2014-2018

2013

2013

2013

OPERATION IMMERSION, KY National Guard

- Experienced military culture through a 4 day immersion experience

TEACHING ASSISTANT, Introduction to Psychology,

University of Louisville

COHORT-STAFF LIAISON, University of Louisville

ICF AUDIT COMMITTEE, VA Boston Healthcare System

- Performed audits of proper informed consent and HIPAA authorization documentation for all active studies at the VA Boston Healthcare System.

AD HOC REVIEWER, Journal of Traumatic Stress

Co-Reviewer: Suzanne Pineles, PhD

AD HOC REVIEWER, Journal of Anxiety Disorders

Co-Reviewer: Suzanne Pineles, PhD

\section{ACADEMIC HONORS AND FUNDING}

2017-2018

2017

2016

2010

2010

2010

2010

2008

2007-2010

2008-2010

2008-2010

2009-2010

2008-2009

2010

2010

2006-2010

2006-2010

2007-2008
Mamie Phipps Clark Research Grant (\$1,500), Psi Chi

Graduate Research Grant (\$500), Graduate Student Council

Graduate Network-College of Arts and Sciences Travel Funding (\$300)

Cum Laude

Departmental Honors in Psychology

Undergraduate Research Scholar

University Honors with Thesis

Study Abroad Scholarship

Psychology Honors Student Advisory Council

Chi Beta Phi (Scientific Honorary Club), The University of Memphis Chapter

Psi Chi, The University of Memphis Chapter

Psi Chi Vice President, The University of Memphis Chapter

Psi Chi Events Committee Head, The University of Memphis Chapter

Selected Presenter at the Tennessee Collegiate Honors Council, conference held annually featuring presenters from the honors programs of the major Tennessee institutions

Selected Presenter at Posters at the Capitol, presentation at the state capitol featuring the top student researchers at each of the major Tennessee institutions

Departmental Honors Program (Psychology)

Helen Hardin University Honors Program

Dean's List 
International Society for Traumatic Stress Studies Gender and Trauma Special Interest Group

2016-2017

International Society for Traumatic Stress Studies

2016-2017

Association for Psychological Science

2011

Association for Behavioral and Cognitive Therapies

2011

Child Maltreatment and Interpersonal Violence Special Interest Group (ABCT) 